Check for updates

Cite this: Mater. Adv., 2021, 2, 47

Received 25th August 2020 Accepted 16th November 2020

DOI: $10.1039 / d 0 m a 00643 b$

rsc.li/materials-advances

\section{Polymorphism in metal halide perovskites}

\begin{abstract}
Aida Alaei, (D) Abigail Circelli, Yihang Yuan, Yi Yang (iD) and Stephanie S. Lee (DD*
Metal halide perovskites (MHPs) are frontrunners among solution-processable materials for lightweight, large-area and flexible optoelectronics. These materials, with the general chemical formula $\mathrm{AMX}_{3}$, are structurally complex, undergoing multiple polymorph transitions as a function of temperature and pressure. In this review, we provide a detailed overview of polymorphism in three-dimensional MHPs as a function of composition, with $\mathrm{A}=\mathrm{Cs}^{+}, \mathrm{MA}^{+}$, or $\mathrm{FA}^{+}, \mathrm{M}=\mathrm{Pb}^{2+}$ or $\mathrm{Sn}^{2+}$, and $\mathrm{X}=\mathrm{Cl}^{-}, \mathrm{Br}^{-}$, or $\mathrm{I}^{-}$. In general, perovskites adopt a highly symmetric cubic structure at elevated temperatures. With decreasing temperatures, the corner-sharing $\mathrm{MX}_{6}$ octahedra tilt with respect to one another, resulting in multiple polymorph transitions to lower-symmetry tetragonal and orthorhombic structures. The temperatures at which these phase transitions occur can be tuned via different strategies, including crystal size reduction, confinement in scaffolds and (de-)pressurization. As discussed in the final section of this review, these solid-state phase transformations can significantly affect optoelectronic properties. Understanding factors governing these transitions is thus critical to the development of highperformance, stable devices.
\end{abstract}

\section{Introduction}

As conversion efficiencies of metal halide perovskite (MHP) solar cells skyrocket past $25 \%,{ }^{1}$ research in the fundamental parameters governing MHP performance in optoelectronic devices, including solar cells, light-emitting diodes, transistors, and sensors, continues to rise exponentially. This class of materials, adopting the general perovskite composition of $\mathrm{AMX}_{3}$ where $\mathrm{X}$ represents halide ions of $\mathrm{Cl}^{-}, \mathrm{Br}^{-}$or I${ }^{-}$, exhibit superior light absorption and charge mobilities compared to their organic molecular and polymeric counterparts, ${ }^{2}$ as well as remarkable defect tolerance that enables their high performance upon solution processing., ${ }^{3,4}$

Intricately tied to the performance of these materials is the specific arrangement adopted by the ions within the crystalline lattice. All MHPs exhibit different polymorphs, i.e. solid-state crystal structures, as a function of temperature and pressure. The optoelectronic properties of MHPs can vary significantly depending on the specific polymorph present. $\mathrm{CsPbI}_{3}, \mathrm{FAPbI}_{3}$ and $\mathrm{CsSnI}_{3}$, for example, all adopt a non-perovskite, insulating phase at room temperature that cannot be used as active layers in optoelectronic devices. ${ }^{5-8}$ Significant research effort has thus focused on developing methods to trap the metastable, active perovskite phases of these compounds. ${ }^{9,10}$ In other systems, the relationship between polymorphism and optoelectronic properties is less drastic, but important nonetheless. The $\mathrm{MAPbI}_{3}$

Department of Chemical Engineering and Materials Science, Stevens Institute of Technology, Hoboken, NJ, USA. E-mail: stephanie.lee@stevens.edu tetragonal-to-cubic transition, for example, occurs within the operating range of solar cells around $330 \mathrm{~K}$ and can impact, for example, charge carrier dynamics. ${ }^{11}$ Understanding and controlling polymorphism in this class of materials is necessary to ensure long-lasting, reliable performance of MHP-based optoelectronic devices.

In this review, we aim to present a systematic and comprehensive picture of polymorphism in three-dimensional MHPs, beginning with a general classification of perovskite polymorphs and a comparison of all the known polymorph transition temperatures across 17 different three-dimensional MHPs. These MHPs represent "pure" compositions, rather than mixed compositions in which one or all of the components is a mixture of different ionic species (e.g. $\mathrm{MA}_{x} \mathrm{Cs}_{1-x^{-}}$ $\left.\mathrm{Pb}_{y} \mathrm{Sn}_{1-y} \mathrm{Cl}_{z} \mathrm{Br}_{3-z}\right)$. Overall, all MHPs adopt a high-symmetry cubic phase at elevated temperatures, transitioning to lowersymmetry polymorphs upon decreasing temperature as a result of octahedral tilting. For MHPs with organic A-site cations, the orientation and motion of the cation with respect to the metalhalide framework must also be considered. Strategies, including crystal size reduction and pressurization, employed to shift polymorph transition temperatures and relative thermodynamic stabilities are discussed. An overview of how optoelectronic properties vary with different polymorphs is also provided.

\section{Classifying perovskite polymorphs}

First discovered by Russian mineralogist Lev Perovski, perovskites are a class of materials that adopt the structure of calcium titanium oxide, with a general chemical formula of $\mathrm{AMX}_{3}$. 

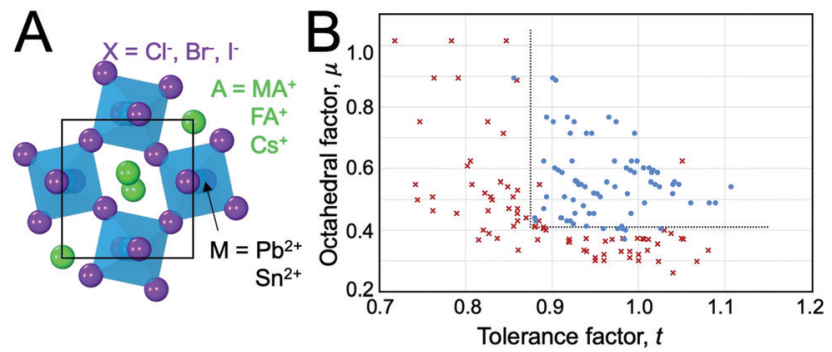

Fig. 1 (A) Perovskite structure comprising corner-sharing octahedra. (B) Plot of octahedral factors versus tolerance factors based on anion-dependent cationic radii. Blue circles represent compounds that form the perovskite structure at room temperature and pressure, while red $x$ 's represent those that do not. Adapted from ref. 15. Copyright 2016, Royal Society of Chemistry.

In the perovskite structure, $\mathrm{X}$ ions form corner-sharing octahedra with $\mathbf{M}$ ion centers, while $\mathrm{A}$ ions occupy the spaces between octahedra. A schematic of the perovskite structure highlighting the corner sharing octahedra is provided in Fig. 1A. This particular structure represents an orthorhombic phase in which the octahedra are tilted relative to one another. The extent and direction of octahedral tilting define the different perovskite polymorphs and are a consequence of a mismatch between the sizes of the ions comprising the perovskite structure. ${ }^{12}$ The ideal size of the A-site cation can be predicted by the Goldschmidt tolerance factor, $t:^{13}$

$$
t=\frac{r_{\mathrm{A}}+r_{\mathrm{X}}}{\sqrt{2}\left(r_{\mathrm{M}}+r_{\mathrm{X}}\right)}
$$

where $r_{\mathrm{A}}, r_{\mathrm{M}}$, and $r_{\mathrm{X}}$, represent the radii of the $\mathrm{A}, \mathrm{M}$ and $\mathrm{X}$ ions, respectively. For MHPs, the size of the A cation is generally smaller than required for $t=1 .{ }^{14}$ Recently, the use of anion-dependent cation radii to more accurately predict perovskite formation has been proposed ${ }^{15}$ in conjunction with the octahedral factor, $\mu$, defined as: ${ }^{16}$

$$
\mu=\frac{r_{\mathrm{M}}}{r_{\mathrm{X}}}
$$

As displayed in Fig. 1B, Travis and co-workers found that combining revised tolerance factors and octahedral factors led to the accurate prediction of whether or not compounds form perovskite structures at room temperature and pressure based on threshold values of $t \leq 1.06$ and $\mu>0.41 .^{15}$

At ambient pressure, perovskites can undergo multiple solid-state phase transitions as a function of temperature. In the highest-symmetry cubic structure with a $\mathrm{M}-\mathrm{X}-\mathrm{M}$ angle of $180^{\circ}$ that appears at elevated temperatures, the corner-sharing octahedra are aligned in all directions. With decreasing temperature, the octahedra tilt due to a mismatch between the size of the A-site cation and the metal-halide framework. Polymorphs thus represent different extents of tilting of the corner-sharing octahedra. The tilting can be described in Glazer notation, ${ }^{17}$ which assigns either an in-phase $(+)$ or outof-phase $(-)$ rotation of octahedra along each of the three spatial dimensions, $x$ (first position), $y$ (second position), and $z$ (third position). The amplitude of these rotations is indicated
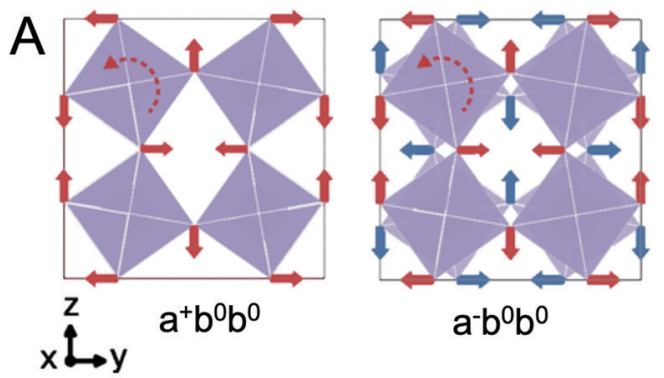

$a-b^{0} b^{0}$

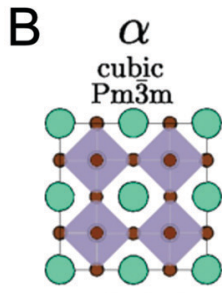

$a^{0} a^{0} a^{0}$

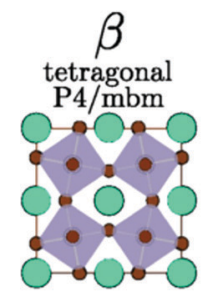

$a^{0} a^{0} c^{+}$

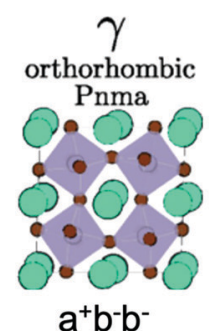

$a^{+} b^{-} b^{-}$

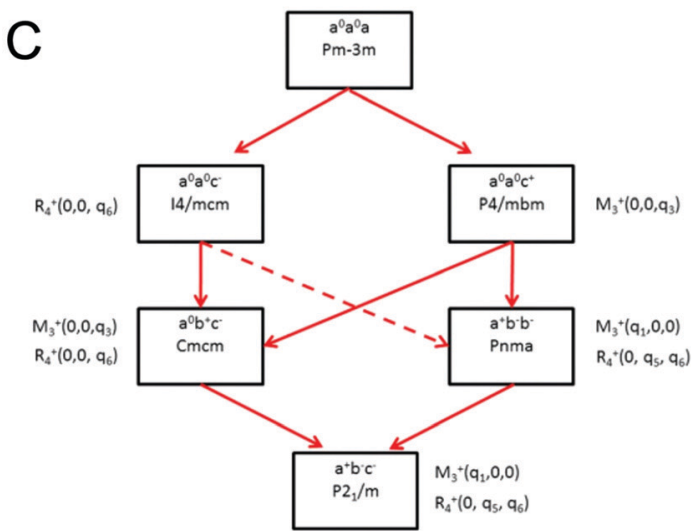

Fig. 2 (A) Illustrations of different octahedral tilting directions and their corresponding identifier in Glazer notation. (B) Solid-state phases observed in MHPs, from the high-temperature, high-symmetry cubic structure to the low-temperature, low-symmetry orthorhombic structure. Adapted with permission from ref. 12. Copyright 2018, American Physical Society. (C) Flow diagram of phase transitions in organic MHPs and all-inorganic MHPs. The dashed red line indicates that transitions from $14 / \mathrm{mcm}$ to Pnma symmetry must be a first order transition. Reproduced with permission from ref. 18. Copyright 2016, Royal Society of Chemistry.

by lower case letters. As detailed by Bechtel and co-workers in Fig. 2A, a perovskite structure characterized as $a^{+} b^{0} b^{0}$ in Glazer notation exhibits in-phase octahedral tilting along the $x$-axis, with no tilting along other axes. ${ }^{12}$ On the other hand, a structure characterized as $\mathrm{a}^{-} \mathrm{b}^{0} \mathrm{~b}^{0}$ exhibits out-of-phase octahedral tilting in the $x$ direction. For a structure characterized by $\mathrm{a}^{+} \mathrm{b}^{-} \mathrm{b}^{-}$, in-plane octahedral rotation occurs along the $x$-direction, while out-of-plane tilting occurs along the $y$ - and $z$-directions. The amplitude of tilting is the same in the $y$-and $z$-directions, but different from the $x$-direction, as indicated by the different lowercase letters $a$ and $b$. In general, perovskites undergo a cubic-to-tetragonal transition, followed by a tetragonal-to-orthorhombic transition with decreasing temperature. 
The cubic, tetragonal, and orthorhombic phases are represented by the Greek letters $\alpha, \beta$ and $\gamma$, respectively. Fig. 2B displays the general classification for these phases. ${ }^{18}$ For all MHPs characterized thus far, octahedral tilting in the $\gamma$-phase is characterized by $\mathrm{a}^{+} \mathrm{b}^{-} \mathrm{b}^{-}$, resulting in Pnma symmetry, while the tetragonal phase can adopt either $P 4 / \mathrm{mbm}$ symmetry with in-phase octahedral tilting denoted by $\mathrm{a}^{0} \mathrm{a}^{0} \mathrm{c}^{+}$or $14 / \mathrm{mcm}$ symmetry with out-ofphase octahedral tilting denoted by $\mathrm{a}^{0} \mathrm{a}^{0} \mathrm{c}^{-}$. Fig. 2C displays a flow diagram of phase transitions observed in hybrid and allinorganic perovskites, including those outside of the halide perovskite family. ${ }^{18}$

For the sub-class of optoelectronically-active perovskites that are the topic of this review, the use of halide anions $\left(\right.$ e.g. $\mathrm{Cl}^{-}$, $\mathrm{Br}^{-}, \mathrm{I}^{-}$) in the $\mathrm{X}$ position imposes restrictions on the options for $\mathrm{A}$ and $\mathrm{M}$ cations. Compared to other anions common to perovskite structures, such as $\mathrm{O}_{2}{ }^{-}$, halide anions have smaller negative charge and larger ionic radii. ${ }^{19}$ As such, A-site cations have thus far been limited to organic methylammonium and formamidinium and inorganic cesium, while $\mathrm{M}^{\mathrm{II}}$ cations are largely restricted to heavier group IV elements $\left(\right.$ e.g. $\mathrm{Sn}^{2+}$ and $\left.\mathrm{Pb}^{2+}\right) \cdot{ }^{19}$

Fig. 3 displays the solid-state phase transition temperatures and space groups reported for bulk MHP crystals, including $\mathrm{CsPbCl}_{3},{ }^{20-23} \mathrm{CsPbBr}_{3},{ }^{24-26} \mathrm{CsPbI}_{3},{ }^{27,28} \mathrm{CsSnCl}_{3}{ }^{29,30} \mathrm{CsSnBr}_{3},{ }^{31,32}$ $\mathrm{CsSnI}_{3},{ }^{29,33,34} \mathrm{MAPbCl}_{3},{ }^{35-37} \mathrm{MAPbBr}_{3},{ }^{36,38-40} \mathrm{MAPbI}_{3},{ }^{36,41-43}$ $\mathrm{MASnCl}_{3},{ }^{30} \mathrm{MASnBr}_{3},{ }^{8} \mathrm{MASnI}_{3},{ }^{44,45} \mathrm{FAPbCl}_{3},{ }^{46} \mathrm{FAPbBr}_{3},{ }^{47}$ $\mathrm{FAPbI}_{3},{ }^{6,8} \mathrm{FASnBr}_{3},{ }^{48}$ and $\mathrm{FASnI}_{3} .{ }^{47}$ To the best of our knowledge, the crystal structure of $\mathrm{FASnCl}_{3}$ has not been reported. As observed from the figure, all perovskites adopt a cubic $P m \overline{3} m$ structure at elevated temperatures. In general, chlorine-based derivatives retain the cubic structure to relatively lower temperatures compared to bromine and iodine derivatives with the same A-site and metal cations. With a smaller ionic radius, the tolerance factors for chlorine derivatives are closer to 1 , rendering the cubic phase more stable. For all derivatives, the symmetry of the crystal structure decreases as temperature is lowered, following the flow diagram displayed in Fig. 2C. Furthermore, MHPs with organic A-site cations generally form the cubic phase at room temperature due to the relatively larger size of these cations compared to $\mathrm{Cs}^{+}$. For reference, $\mathrm{Cs}^{+}$has an ionic radius of $1.88 \AA^{15}{ }^{15}$ Estimated effective ionic radii generally fall in the range of 2.03-2.38 $\AA$ for $\mathrm{MA}^{+}$and 2.24-2.53 $\AA$ for $\mathrm{FA}^{+}$. $^{15,49-51}$

We note there are some discrepancies in the literature on phase transition temperatures and space groups observed for specific compositions. In 1987, for example, Poglitsch and Weber reported the space groups of the low temperature phases of $\mathrm{MAPbCl}_{3}, \mathrm{MAPbBr}_{3}$ and $\mathrm{MAPbI}_{3}$ to be $P 222_{1}, \mathrm{Pna2}_{1}$, and Pna $2_{1}$, respectively. ${ }^{36}$ These assignments have been reassigned to Pnma based on recent high resolution X-ray and neutron diffraction experiments. ${ }^{35,43,52}$ For $\mathrm{MAPbBr}_{3}$, there are further conflicting reports about the existence of a $P 4 / \mathrm{mmm}$ tetragonal phase in between the orthorhombic phase and $I 4 / \mathrm{mcm}$ tetragonal phase, with neutron scattering ${ }^{52}$ and X-ray diffraction experiments ${ }^{53}$ unable to detect this phase.

\section{Polymorphism in all-inorganic perovskites}

For perovskites comprising halide anions in the X-site, cesium is the only elemental ion with a sufficiently large radius to support the perovskite framework. ${ }^{19}$ To date, the most promising inorganic halide perovskites for optoelectronic devices are $\mathrm{CsPbX}_{3}$ and $\mathrm{CsSnX}_{3}$ where $\mathrm{X}=\mathrm{Cl}^{-}, \mathrm{Br}^{-}$, or $\mathrm{I}^{-}{ }^{54}$ The first reports on the crystal structures of these compounds date back to the late 1950s to early $1970 \mathrm{~s},{ }^{29,55-57}$ but it was not until 2015 that the first all-inorganic light-emitting diodes comprising $\mathrm{CsPbBr}_{3}$ as the photoactive layer ${ }^{58}$ and solar cells comprising $\mathrm{CsPbI}_{3}$ as the photoactive layer ${ }^{59}$ were successfully fabricated. Since then, inorganic MHP-based devices have been demonstrated for a variety of devices, ${ }^{60,61}$ including photodetectors, ${ }^{62,63}$ solar cells, ${ }^{64,65}$ transistors $^{66,67}$ and light-emitting diodes. ${ }^{68-70}$

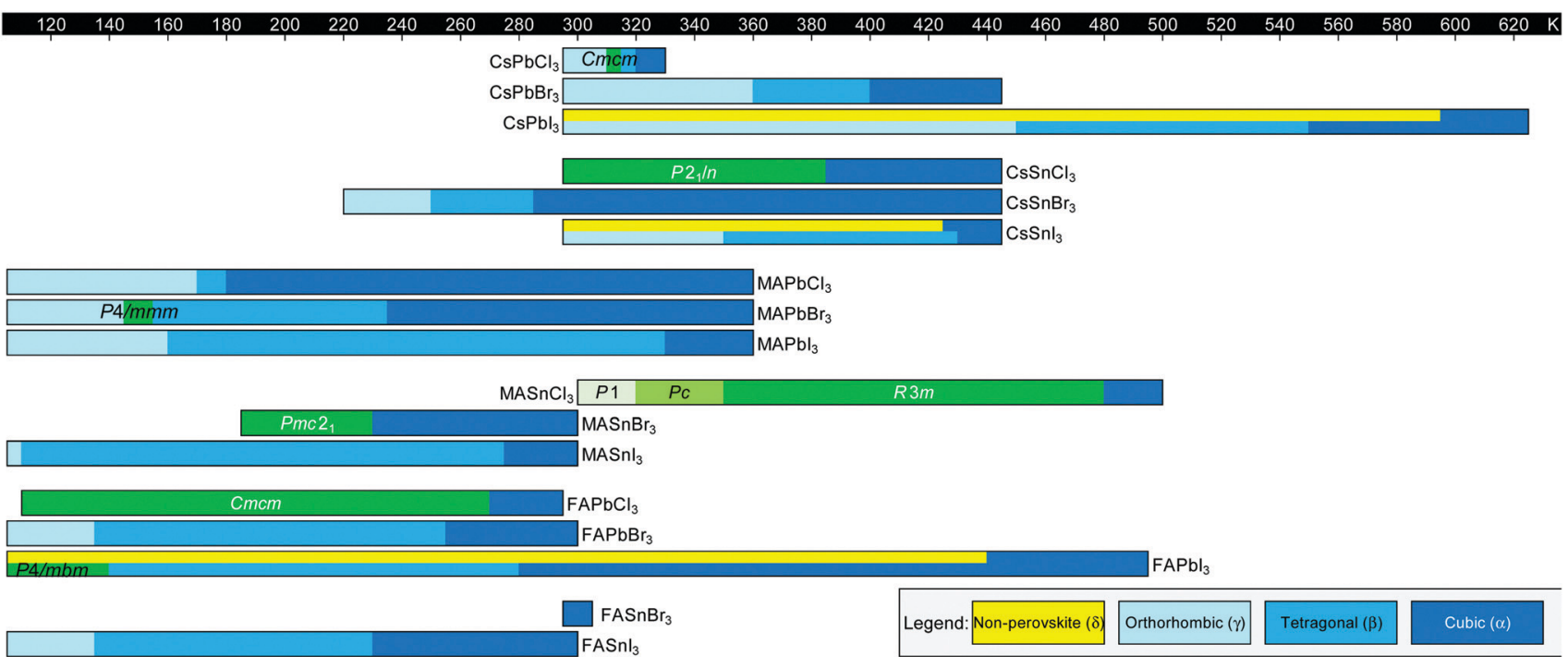

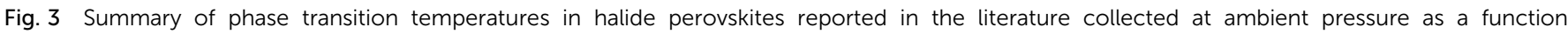

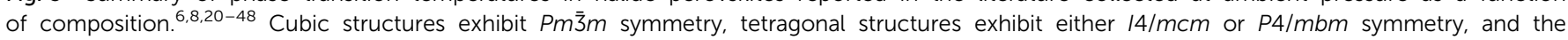
orthorhombic phase exhibits Pnma symmetry, unless otherwise noted. Green colors indicate phases not represented by the above categories. 
Promisingly, $\mathrm{CsPbI}_{3}$-based solar cells recently achieved record efficiencies of $19 \% .^{71}$

Compared to MHPs utilizing organic molecules as the A-site cation, inorganic MHPs comprising inorganic $\mathrm{Cs}^{+}$cations are expected to exhibit enhanced thermal stability. ${ }^{54}$ However, these inorganic perovskites have other critical issues related to degradation and polymorph transitions. Sn-Based perovskites exhibit smaller bandgaps compared to their Pb-based counterparts, $1.3 \mathrm{eV}$ for $\mathrm{CsSnI}_{3}$ compared to $1.7 \mathrm{eV}$ for $\mathrm{CsPbI}_{3}$, but suffer from rapid oxidation of $\mathrm{Sn}^{2+}$ to the more stable state of $\mathrm{Sn}^{4+}$. In the $\mathrm{Pb}$ family, $\mathrm{CsPbCl}_{3}$ and $\mathrm{CsPbBr}_{3}$ are air-stable in the perovskite phase at ambient temperatures and pressures but their relatively large bandgaps of 2.99 and $2.31 \mathrm{eV}^{72}$ make them less attractive for light harvesting applications. On the other hand, the perovskite phases of $\mathrm{CsPbI}_{3}$ possess reasonable bandgaps around $1.7 \mathrm{eV}$ but these phases are only stable at elevated temperatures. Of all the $\mathrm{CsMX}_{3}$ compounds, $\mathrm{CsPbI}_{3}$ and $\mathrm{CsSnI}_{3}$ have the smallest tolerance factors of 0.89 and 0.91 (based on anion-dependent A-site cation radii) and octahedral factors of 0.47 and 0.44 , respectively. ${ }^{15}$ This mismatch between the A-site cation size and the perovskite framework renders these systems less stable compared to other $\mathrm{CsMX}_{3}$ compounds where $\mathrm{M}=\mathrm{Pb}^{2+}$ or $\mathrm{Sn}^{2+}$ and $\mathrm{X}=\mathrm{Cl}^{-}$or $\mathrm{Br}^{-}$. At room temperature, $\mathrm{CsPbI}_{3}$ and $\mathrm{CsSnI}_{3}$ both exist in a yellow, non-perovskite polymorph, ${ }^{55,73}$ referred to as the $\delta$ phase, exhibiting large bandgaps of around 2.8 and $2.55 \mathrm{eV}$, respectively. ${ }^{34,74}$ The $\delta$ phase is characterized by isolated double $\mathrm{MX}_{6}$ octahedra (Fig. $4 \mathrm{~A}$ ).

While all four phases of $\mathrm{CsSnI}_{3}$ were identified and characterized $^{29,75}$ decades prior to the fabrication of the first perovskite-based solar cell by Kojima and coworkers in $2009,{ }^{76}$ some confusion initially surrounded the room temperature perovskite structure of $\mathrm{CsPbI}_{3}$. Many early reports on $\mathrm{CsPbI}_{3}$ based optoelectronic devices described the room temperature metastable perovskite phase as the cubic $\alpha$ phase. Recent studies, however, have found that $\mathrm{CsPbI}_{3}$ undergoes the same cubic-tetragonal and tetragonal-orthorhombic phase transitions upon cooling as other perovskites. ${ }^{27,28}$ Fig. 4A displays the phase transitions of $\mathrm{CsPbI}_{3}$ as a function of the thermal history. At room temperature, $\mathrm{CsPbI}_{3}$ adopts the non-perovskite $\delta$ phase. Upon heating above $587 \mathrm{~K}$, this phase converts directly to the cubic $\alpha$ phase. $^{27}$ If the $\alpha$ phase is then slowly cooled, it undergoes a transition to the tetragonal $\beta$ phase at $554 \mathrm{~K}$ and then to the orthorhombic $\gamma$ phase at $457 \mathrm{~K}$. Comparing two different methods of stabilizing the black phase of $\mathrm{CsPbI}_{3}$ at room temperature via Rietveld refinement of powder diffraction patterns, Sutton and coworkers confirmed that the $\gamma$ phase is present at room temperature, not the cubic $\alpha$ phase. $^{28}$

At room temperature, the $\gamma$ phases of both $\mathrm{CsSnI}_{3}$ and $\mathrm{CsPbI}_{3}$ are unstable and will spontaneously convert to the insulating $\delta$ phases, ${ }^{75}$ even when stored under vacuum. ${ }^{77}$ Using low-frequency Raman spectroscopy to monitor phonon modes in a $\mathrm{CsPbI}_{3}$ crystalline film deposited via drop casting from dimethyl sulfoxide onto a $\mathrm{SiO}_{2}$ substrate, we found this transition to occur within $6 \mathrm{~min}$ of air exposure (Fig. 4B). ${ }^{78}$ The transition itself was rapid and completed within time resolution limit of the measurements (e.g. within one minute).
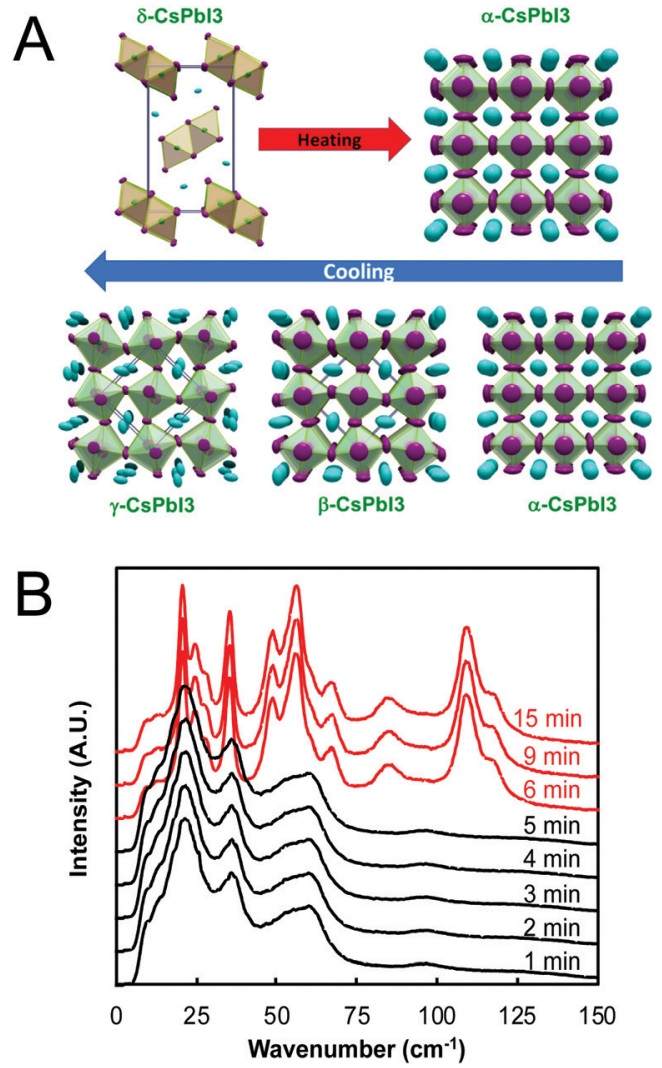

Fig. 4 (A) Temperature-dependent phase transitions of $\mathrm{CsPbl}_{3}$ at ambient pressure. Reproduced with permission from ref. 27. Copyright 2018, American Chemical Society. (B) Room-temperature low-frequency Raman spectra of a drop cast $\mathrm{CsPb}_{3}$ film as a function of exposure time to air $\left(\lambda_{\mathrm{ex}}=976 \mathrm{~nm}\right) . \mathrm{CsPb}_{3}$ initially adopted the $\gamma$ phase (black) upon cooling from $610 \mathrm{~K}$ before converting to the $\delta$ phase (red) between 5 and 6 min of air exposure. Adapted with permission from ref. 78. Copyright 2020, Royal Society of Chemistry.

Stabilizing the active black phases of these compounds at room temperature has thus been an area of intense research focus over the past five years.

\section{Polymorphism in organometallic perovskites}

Organic MHPs with methylammonium (MA+) and formamidinium (FA+) as the A-site cation represent the most extensively studied compositions of MHPs for optoelectronic applications to-date. These ions are larger than $\mathrm{Cs}^{+}$, resulting in tolerance factors closer to, and in some cases larger than $1{ }^{79}$ As displayed in Fig. 3, phase transitions in organic MHPs are similar to inorganic perovskites. These compounds adopt a high symmetry cubic phase at elevated temperatures and transition to lower symmetry structures via octahedral tilting upon cooling. Unlike inorganic MHPs with a simple atomic A-site cation, however, phase transitions in organic MHPs possess additional complexity associated with orientation and rotation of the asymmetric molecular cations in the interstices of the cornersharing $\mathrm{MX}_{6}$ octahedra. ${ }^{80}$ The specific orientations adopted by the A-site cation may in turn affect optoelectronic properties, such as the bandgap. ${ }^{81}$ 
Methylammonium lead iodide (MAPbI $)$. $\mathrm{MAPbI}_{3}$, one of the intensely studied compositions among halide perovskites, was first reported by Weber in $1947 .{ }^{82}$ This compound undergoes two phase transitions upon cooling, a cubic-to-tetragonal transition at $330 \mathrm{~K}$ and a tetragonal to orthorhombic transition at $160 \mathrm{~K}^{83} \mathrm{In}$ each of these phases, the $\mathrm{MA}^{+}$cation is surrounded by a different environment. The $\mathrm{MA}^{+}$cation itself is asymmetric and can rotate about and along the $\mathrm{C}-\mathrm{N}$ axis. In recent years, rotational dynamics of the $\mathrm{MA}^{+}$cation in these phases have been studied by calorimetry, ${ }^{84,85}$ dielectric spectroscopy, ${ }^{85-87}$ computational methods, ${ }^{88-92}$ quasielastic and inelastic neutron scattering ${ }^{93-97}$ nuclear magnetic resonance (NMR) spectroscopy ${ }^{98-101}$ infrared spectroscopy, ${ }^{83,84,102}$ isotopic substitution, ${ }^{103}$ and Raman spectroscopy. ${ }^{104}$

In the cubic phase, which is stable above $330 \mathrm{~K}$, early magnetic resonance experiments found that the $\mathrm{MA}^{+}$cation can rotate on the picosecond timescale within the interstitial spaces between corner-sharing $\mathrm{PbI}_{6}$ octahedra. ${ }^{105}$ In 2015, Weller and co-workers used neutron powder diffraction to provide a comprehensive picture of $\mathrm{MA}^{+}$cation dynamics in the range of $100-352 \mathrm{~K} .^{43} \mathrm{Fig} .5 \mathrm{~A}$ displays a $\mathrm{MAPbI}_{3}$ unit cell in the cubic phase, with atomic displacement parameter (ADP) ellipsoids representing a 50\% probability of locations of the hydrogen atoms at the ends of the $\mathrm{MA}^{+}$cations. As observed from the figure, the $\mathrm{MA}^{+}$ion appears disordered in the cubic phase. Later studies revealed preferential alignment of the $\mathrm{MA}^{+}$ cations based on four-fold rotational symmetry of the $\mathrm{C}-\mathrm{N}$ axis and three-fold rotational symmetry about the $\mathrm{C}-\mathrm{N}$ axis. ${ }^{97,106,107}$ Employing single crystal neutron diffraction studies, Ren and coworkers found that the $\mathrm{MA}^{+}$cations preferentially align along the [011] (edge), [111] (diagonal), and [100] (face) directions. ${ }^{108}$ These experiments also revealed that the middle point of the $\mathrm{C}-\mathrm{N}$ bond is located slightly off-center due to interactions between the amine group of $\mathrm{MA}^{+}$and iodine atoms.

Upon decreasing the temperature below $330 \mathrm{~K}, \mathrm{MAPbI}_{3}$ undergoes a phase transition to the tetragonal $\beta$ phase. Here the $\mathrm{PbI}_{6}$ octahedra are tilted compared to the cubic phase, with an average $\mathrm{Pb}-\mathrm{I}-\mathrm{Pb}$ bond angle of $165.3^{\circ}$. Fig. $5 \mathrm{~b}$ displays one configuration of the tetragonal phase at $180 \mathrm{~K}$ for $\mathrm{MAPbI}_{3}$ with ADP ellipsoids at $50 \%$ probability. ${ }^{43}$ In this phase, the $\mathrm{NH}_{3}$ group adopts four distinct positions, while the $\mathrm{CH}_{3}$ group adopts eight distinct positions. ${ }^{108}$ Although the organic cation is more confined in the tetragonal phase compared to cubic phase, and exhibits slower rotational dynamics, ${ }^{105}$ four-fold rotation of $(\mathrm{C}-\mathrm{N})$ axis $\mathrm{C}_{4}$ and three-fold rotation around $(\mathrm{C}-\mathrm{N})$ axis $\mathrm{C}_{3}$ is still possible. ${ }^{97,106,107}$ Elastic and quasi-elastic neutron scattering techniques and group theoretical analysis revealed the room temperature relaxation times of and around the $\mathrm{C}-\mathrm{N}$ axis to be approximately 5 and 1 ps, respectively. ${ }^{94,106}$

It should be noted that the crystal structure classification of tetragonal $\mathrm{MAPbI}_{3}$ is still being debated, in part due to extensive twinning that complicates structure determination. ${ }^{109,110}$ A centrosymmetric $I 4 / \mathrm{mcm}$ space group for tetragonal $\mathrm{MAPbI}_{3}$ was proposed by Poglitsch and Weber in $1987 .{ }^{36}$ In 2013, Stoumpos and coworkers reported instead a non-centrosymmetric $14 \mathrm{~cm}$ space group due to off-centering of the $\mathrm{MA}^{+}$ cation along the $c$-axis. ${ }^{111} \mathrm{~A}$ later report suggested that noncentrosymmetric tetragonal $\mathrm{MAPbI}_{3}$ was achieved through static distortion of the $\mathrm{Pb}-\mathrm{I}$ framework via second harmonic generation analysis. ${ }^{112}$ Subsequent second harmonic generation rotational anisotropy experiments capable of distinguishing surface and bulk signals, however, determined that tetragonal $\mathrm{MAPbI}_{3}$ indeed adopts the centrosymmetric $14 / \mathrm{mcm}$ space group. ${ }^{113}$ Structural rearrangement at perovskite surfaces may lead to the formation of noncentrosymmetric domains that are not present in the bulk, as observed in low-temperature scanning tunneling microscopy images of $\mathrm{MAPbBr}_{3}$ crystals. ${ }^{114}$ Noncentrosymmetric structures in MHPs are expected to exhibit ferroelectricity and Rashba splitting due to spin-orbit coupling interactions with charge carriers. With significant implications to fundamental device physics and applications, intensive research efforts continue to focus on definitive structure determination in these materials.

As displayed in Fig. 5C, the $\mathrm{MA}^{+}$cation is in its most confined state in the low temperature orthorhombic $\gamma$ phase $(T<160 \mathrm{~K})$, for which the average $\mathrm{Pb}-\mathrm{I}-\mathrm{Pb}$ bond angle of $154.51^{\circ}$. In this phase, the MA+ cations are completely ordered in an alternating head-to-tail configuration with the $\mathrm{NH}_{3}$ groups of $\mathrm{MA}^{+}$closer to the inorganic framework compared to the $\mathrm{CH}_{3}$ groups. ${ }^{43}$ Relaxation times of the $\mathrm{MA}^{+}$cation were found to be orders of magnitude larger than those expected for a rigid rotator in the same temperature range due to restrictions on motion
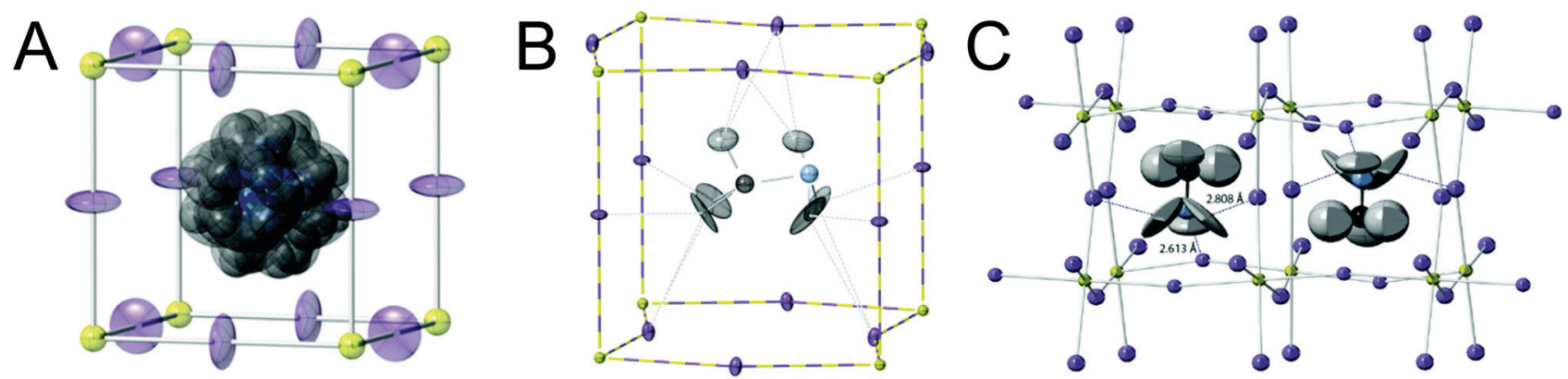

Fig. 5 Depictions of $\mathrm{MA}^{+}$cation orientations in the (A) cubic phase with ADP ellipsoids at $50 \%$ probability, (B) one orientation of the tetragonal phase with ADP ellipsoids at $50 \%$ probability, and (C) orthorhombic phase with ADP ellipsoids at $90 \%$ probability of MAPbl 3 , as determined by powder neutron diffraction experiments. Adapted with permission from ref. 43. Copyright 2015, Royal Society of Chemistry. 
imposed by the $\mathrm{Pb}-\mathrm{I}$ framework. ${ }^{115}$ This configuration promotes hydrogen bonding between the $\mathrm{NH}_{3}$ group of the $\mathrm{MA}^{+}$cation and the framework. ${ }^{4,116}$ While four-fold rotation is not allowed in this polymorph, three-fold rotation about the $\mathrm{C}-\mathrm{N}$ axis is possible, ${ }^{97,106,107}$ with estimated activation energies of $56 \mathrm{meV}$ and $120 \mathrm{meV}$ for rotations of the $\mathrm{CH}_{3}$ and $\mathrm{NH}_{3}$ tails, respectively. ${ }^{117}$ Using infrared spectroscopy to examine vibrational modes in $\mathrm{MAPbI}_{3}$ single crystals, Schuck and coworkers found that the vibrational mode associated with symmetrical $\mathrm{NH}_{3}$ bending shifted to lower frequencies upon transitioning from the tetragonal to orthorhombic structure due to hydrogen bonding between the amine group on the organic cation and halide ions. ${ }^{118}$ Interestingly, the strength of the interaction depended on the halide composition, with the largest effect observed for $\mathrm{I}^{-}$compared to $\mathrm{Cl}^{-}$and $\mathrm{Br}^{-}$.

These experimental results have been supported by extensive computational modelling of $\mathrm{MA}+$ rotational dynamics. ${ }^{18,94,95,102,119-122}$ Recent molecular dynamics simulations of phase transitions in organic MHPs have found that phase transitions are the result of dipole-dipole interactions between organic cations and hydrogen bonding with the $\mathrm{Pb}-\mathrm{I}$ lattice. ${ }^{116}$ Reduced cation movement with decreasing temperature increases the strength of these interactions, resulting in lattice deformation. ${ }^{121}$ Combining DFT calculations and $a b$ initio molecular dynamics, Deretzis and Magna found that vibrational features of $\mathrm{MAPbI}_{3}$ are strongly affected by the orientation of the organic cation in the low temperature orthorhombic phase, with the tetragonal-orthorhombic phase transition occurring to relax stress via rearrangement of the $\mathrm{MA}^{+}$cation in an orientation that can reduce local stretching of ionic bonds in the inorganic framework. ${ }^{120}$

Formamidinium lead iodide. The second most widely studied organic cation used in three-dimensional MHPs is formamidinium $\left(\mathrm{FA}^{+}\right) .{ }^{123,124}$ With a bulkier size compared to $\mathrm{MA}^{+}, \mathrm{FA}^{+}$-based MHPs exhibit a smaller bandgap and improved thermal and lattice stability. ${ }^{125,126}$ In general, FA-based MHPs undergo similar temperature-dependent crystal structure transitions as MA-based MHPs, ${ }^{127}$ with the major exception being that $\mathrm{FAPbI}_{3}$ typically exists in a non-perovskite $\delta$ phase at room temperature with $P 6_{3} m c$ symmetry. ${ }^{42}$ Calculated ground state energy differences between $\delta$ and $\alpha-\mathrm{FAPbI}_{3}$ phases have demonstrated that the $\delta$ phase is the thermodynamically-stable phase due to a face-sharing configuration of $\mathrm{PbI}_{6}$ octahedra that results in higher structural stability compared to cornersharing octahedra in the $\alpha$ phase. ${ }^{127}$ Because the $\alpha-\delta$ phase transition in $\mathrm{FAPbI}_{3}$ is reversible in solution, however, the $\alpha$ phase can be kinetically trapped under appropriate processing conditions $^{42}$ to be incorporated into optoelectronic devices.

For $\mathrm{FA}^{+}$cations, there are three primary axes of rotation, with rotation about the $\mathrm{N}-\mathrm{N}$ axis the dominant motion in all phases above $50 \mathrm{~K} .{ }^{107}$ As displayed in Fig. 6A, $\mathrm{FA}^{+}$cations are completely disordered in the high temperature cubic phase and can rotate freely within the inorganic framework. ${ }^{127}$ In this phase, the carbon atom of the $\mathrm{FA}^{+}$cation is located at the center of the inorganic framework. ${ }^{128}$ In the lower temperature tetragonal phase, $\mathrm{FA}^{+}$cations rotate between preferred orientations, (a)
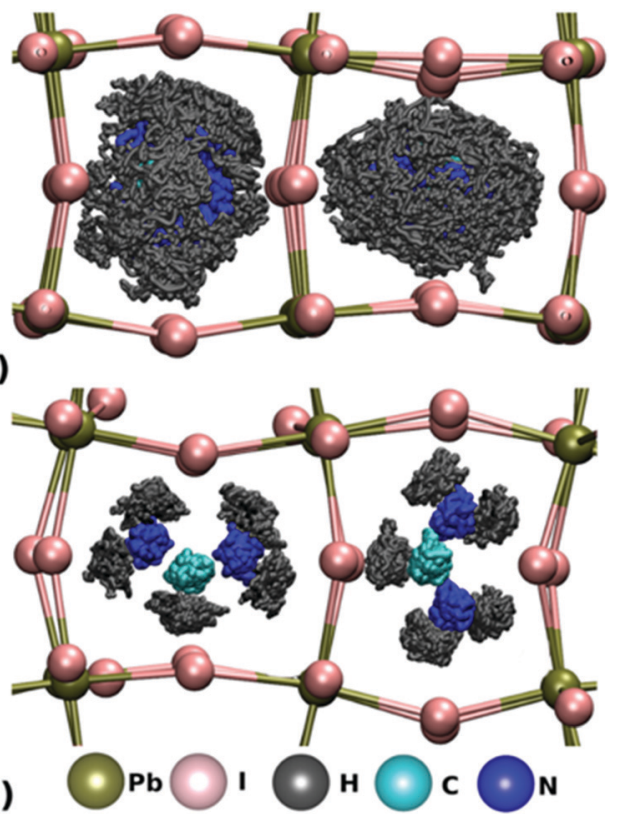

Fig. 6 Molecular dynamics simulations of FA cations within $\mathrm{Pb}-\mathrm{I}$ frameworks in the (A) pseudocubic phase and (B) tetragonal phase. Reproduced with permission from ref. 127. Copyright 2018, American Chemical Society.

as displayed in Fig. 6B. In this phase, $\mathrm{FA}^{+}$cations in adjacent inorganic cages reorient with respect to each other by changing the $\mathrm{H}-\mathrm{C}$ bond direction. This preferred orientation is influenced by $\mathrm{PbI}_{6}$ octahedral tilting, as demonstrated by both experimental and simulation results. ${ }^{127,129}$ In the low-temperature orthorhombic phase, $\mathrm{FA}^{+}$cation rotation is arrested but unlike $\mathrm{MA}^{+}$cations, $\mathrm{FA}^{+}$ cations do not exhibit any long range order. ${ }^{127}$ Instead, their configuration can be described by a glass-like, disordered state. ${ }^{107}$

\section{Influence of crystal size on polymorph transitions}

One of the most promising emerging strategies to stabilize MHPs is to reduce the average crystal size. ${ }^{130}$ The total Gibbs free energy of a crystal, $G_{\mathrm{T}}$, can be expressed as a sum of the volume free energy, $G_{\mathrm{V}}$, and the total surface free energy: ${ }^{131}$

$$
G_{\mathrm{T}}=G_{\mathrm{V}}+\left(\frac{a}{\rho}\right) \frac{A}{V}
$$

where $a$ is the surface energy of the crystal surface, $\rho$ is the bulk crystal density, $A$ is the mean total surface area and $V$ is the mean volume per crystal. As crystals grow the surface area-tovolume ratio, $A / V$, decreases. For bulk crystals, the surface free energy contribution is thus minimal. For bulk crystals, the Gibbs free energy is largely determined by the volume free energy.

For relatively small crystals, on the other hand, the surface free energy contribution to the total Gibbs free energy can be significant. Fig. 7 illustrates the shift in Gibbs free energy upon crystal size reduction of two polymorphs of a compound as a function of temperature. As can be seen from the figure, at temperatures above $T_{\alpha \beta}$, the $\alpha$ phase is favored due to its lower Gibbs free energy compared to the $\beta$ phase. $T_{\alpha \beta}$ represents the 


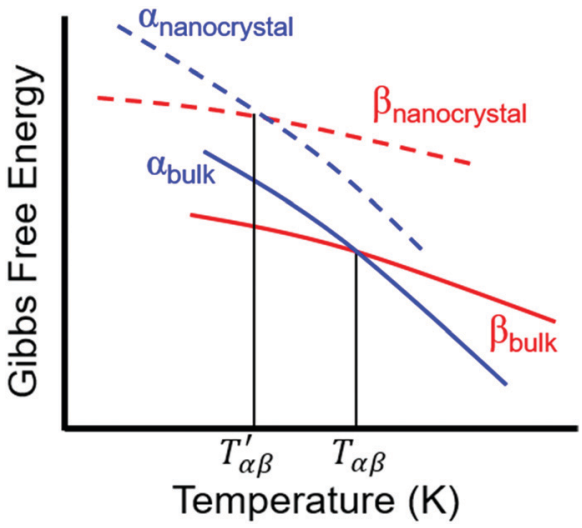

Fig. 7 Comparison of the dependence of the Gibbs free energy on temperature for different polymorphs of a bulk crystal and nanocrystal. Adapted with permission from ref. 130. Copyright 2019, American Chemical Society.

temperature at which phase co-existence occurs. Below $T_{\alpha \beta}$, the $\beta$ phase is thermodynamically preferred. For nanocrystals with large $A / V$ ratios (represented by dashed lines), the Gibbs free energy of both phases increases due to an increased contribution from the surface free energy. If the surface free energy of the $\beta$ phase is larger than the surface free energy of the $\alpha$ phase, the final result is a lowering of the phase transition temperature from $T_{\alpha \beta}$ to $T_{\alpha \beta}^{\prime}$. Indeed, lower surface free energies of higher symmetry polymorphs compared to lower symmetry polymorphs have been recorded for a variety of metal oxide systems. ${ }^{132-135}$ For $\mathrm{CsPbI}_{3}$, DFT calculations found the surface energies of the high symmetry $\gamma$ phase and low symmetry $\delta$ phase to be 0.13 and $2.57 \mathrm{~J} \mathrm{~m}^{-2}$, respectively. ${ }^{136}$

\section{Perovskite quantum dots (PQDs)}

At the smallest length scale, many research efforts have focused on the synthesis of perovskite quantum dots (PQDs) with dimensions in the range of 2-20 nm. ${ }^{137,138}$ Lowering of solidstate phase transition temperatures in these systems has been widely reported, although some confusion has surrounded the precise solid-state phases adopted by PQDs. In the first report of metal halide PQDs in 2015, Protesescu and coworkers synthesized all-inorganic cesium lead halide perovskite QDS $\left(\mathrm{CsPbX}_{3}, \mathrm{X}=\mathrm{Cl}, \mathrm{Br}, \mathrm{I}\right.$, and mixed $\left.\mathrm{Cl} / \mathrm{Br}, \mathrm{Br} / \mathrm{I}\right)$, with sizes in the range of 4-15 $\mathrm{nm}$. XRD patterns collected on the PQDs were used to assign the cubic $\alpha$ phase to all compositions. ${ }^{139}$ These phases were reported to be stable, with only $\mathrm{CsPbI}_{3}$ transitioning to the orthorhombic, non-perovskite $\delta$ phase upon several months of storage. A later report using synchrotron radiation and atomic pair distribution (PDF) to characterize both elastic and inelastic $\mathrm{X}$-ray scattering from PQDs prepared in the same manner, however, found that $\mathrm{CsPbCl}_{3}, \mathrm{CsPbBr}_{3}$ and $\mathrm{CsPbI}_{3}$ QDs all existed in the room temperature $\gamma$ phase observed in bulk crystals. ${ }^{140}$ Here the authors found that the presence of twin boundaries in some cases gave rise to "apparent higher symmetry" observed via $\mathrm{X}$-ray diffraction. In general, while the main peaks in the XRD patterns of the $\gamma$ phase are similar to those of the $\alpha$ phase, the presence of weak superstructure peaks indicate octahedral tilting in the perovskite framework. These findings are supported by $a b$ initio DFT simulations that found crystal size reduction to below $5.6 \mathrm{~nm}$ and $2.7 \mathrm{~nm}$ were needed to thermodynamically stabilize $\gamma-\mathrm{CsPbI}_{3}$ and $\alpha-\mathrm{CsPbI}_{3}$, respectively. ${ }^{141}$

In 2018, Cottingham and Brutchey experimentally examined phase transitions in $\mathrm{CsPbBr}_{3}$ PQDs with average diameters of $9 \mathrm{~nm}$ using temperature-dependent, synchrotron radiation-based total X-ray scattering techniques. ${ }^{142}$ At room temperature, these PQDs were found to exist in the $\gamma$ phase. ${ }^{143}$ The $\gamma$ - $\beta$ transition was observed between $50-59{ }^{\circ} \mathrm{C}$, while the $\beta$ - $\alpha$ transition was observed between 108-117 ${ }^{\circ} \mathrm{C}$. These ranges represent phase transition temperature depressions of at least 29 and $13{ }^{\circ} \mathrm{C}$, respectively, compared to those observed in bulk crystals. In the analogous organic-inorganic hybrid system of $\mathrm{MAPbBr}_{3}$, Liu and coworkers used temperature-dependent photoluminescence measurements to identify the $\beta-\alpha$ transition for PQDs with an average diameter of $3.7 \pm 0.6 \mathrm{~nm}$ at $150 \mathrm{~K},{ }^{144}$ compared to $\sim 236 \mathrm{~K}$ in the bulk. ${ }^{40}$ Close agreement was found between the experimental data and the predicted phase transition temperature between the paraelectric $\alpha$ phase and ferroelectric $\beta$-phase following Ginzburg-LandauDevonshire theory. Fig. 8 displays the size dependence of the critical temperature and Gibbs free energy, decrease and increase, respectively, with decreasing crystal size. As observed from the figure, the critical temperature drops to $0 \mathrm{~K}$ for particle diameters below $2 \mathrm{~nm}$, in agreement with the authors' observation of the absence of phase transitions for PQDs with average diameters of $1.7 \pm 0.4 \mathrm{~nm}$.

Coexistence of the $\gamma$ and $\alpha$ phases of $\mathrm{CsPbBr}_{3}$ PQDs has also been reported. Recently, Brennan and coworkers examined the crystal structure of $\mathrm{CsPbBr}_{3}$ nanocubes with average edge lengths $5 \mathrm{~nm}$ and $10 \mathrm{~nm}$ via lattice-resolved transmission electron microscopy imaging at progressive defocus values. ${ }^{145}$ Finite Fourier transforms of experimental images and simulated images of the $\alpha$ and $\gamma$ phases suggest that $10 \mathrm{~nm}$ diameter $\mathrm{CsPbBr}_{3}$ nanocubes mainly adopt the cubic $\alpha$ phase, with some $\gamma$ phase present. For $5 \mathrm{~nm}$ diameter nanocubes, on the other hand, only the $\alpha$ phase was found to be present.

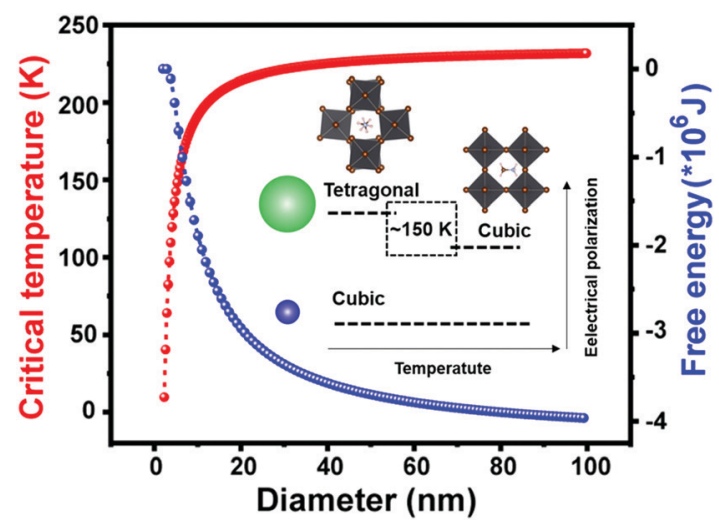

Fig. 8 Critical temperature and Gibbs free energy versus particle diameter for $\mathrm{MAPbBr}_{3} \mathrm{PQDs}$ based on Ginzburg-Landau-Devonshire theory. Reproduced with permission from ref. 144. Copyright 2019, American Chemical Society. 


\section{Scaffold-confined crystals}

Another method of controlling polymorphism via crystal size reduction is to confine crystallization within nanoporous scaffolds, such as controlled porous glass, selectively-etched block copolymers and anodized aluminium oxide. ${ }^{130,146}$ This strategy has been successfully employed to shift phase transition temperatures, including melting points, in a number of different organic and inorganic systems, as summarized in several reviews. ${ }^{130,147,148}$

Recently, our group examined the phase stability of $\mathrm{MAPbI}_{3}$ crystals confined within the cylindrical nanopores of anodized aluminium oxide scaffolds with average pore diameters of 100-250 nm (Fig. 9A). ${ }^{149,150}$ Temperature-dependent X-ray diffraction measurements in the range of $293-373 \mathrm{~K}$ and photoluminescence measurements in the range of $4-300 \mathrm{~K}$ revealed the $\alpha-\beta$ transition temperature to shift from $330 \mathrm{~K}$ for bulk crystals to $170 \mathrm{~K}$ for nanoconfined crystals. Similarly, the $\beta-\gamma$ transition was observed at $80 \mathrm{~K}$ for nanoconfined crystals, compared to $150 \mathrm{~K}$ in the bulk. Fig. 9B displays a comparison of the Gibbs free energy curves as a function of
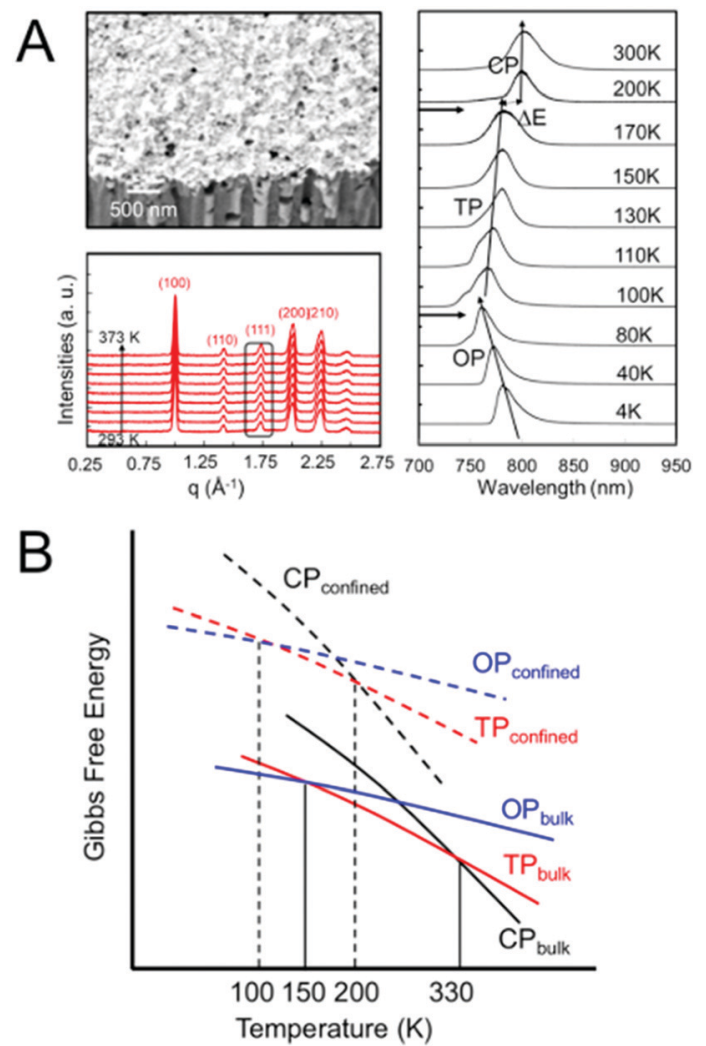

Fig. 9 (A) SEM image of $\mathrm{MAPbl}_{3}$ confined within $100 \mathrm{~nm}$ diameter nanopores of anodized aluminum oxide templates. Temperaturedependent $X$-ray diffraction measurements revealed only the cubic phase to be present in the range of 293-373 K, while temperature-dependent photoluminescence measurements revealed the tetragonal (TP)-cubic (CP) phase transition to occur between 170-200 K and the orthorhombic (OP)-TP transition to occur between 80 and $100 \mathrm{~K}$. (B) Comparison of the dependence of the Gibbs free energy on temperature for different polymorphs of a compound in the bulk and nanocrystal state. Reproduced with permission from ref. 130. Copyright 2019, American Chemical Society. temperature for the different bulk and nanoconfined phases that is consistent with our experimental observations.

Examining nanoconfined $\mathrm{CsPbI}_{3}$ crystallization as a function of AAO pore diameter, $\mathrm{Ma}$ and coworkers found that the black phase of $\mathrm{CsPbI}_{3}$ (reported as the $\alpha$ phase but weak superstructure peaks in the XRD patterns likely indicate the $\gamma$ phase was present) became thermodynamically stable within $41 \mathrm{~nm}$ diameter pores or smaller. ${ }^{151}$ DFT calculations suggested that stabilization of the black $\mathrm{CsPbI}_{3}$ phase at room temperature was due both to increased surface area of nanoconfined crystals and strain introduced at the pore walls. By tuning the processing conditions, we discovered that $\gamma-\mathrm{CsPbI}_{3}$ could be stabilized in AAO pores as large as $250 \mathrm{~nm} .{ }^{152}$ Using wet annealing method in which spun cast samples with solvent remained were immediately annealed at a minimum temperature $373 \mathrm{~K}, \gamma-\mathrm{CsPbI}_{3}$ was formed within the AAO nanopores. Once formed, nanoconfined $\gamma-\mathrm{CsPbI}_{3}$ was found to be stable in a range of 4-610 $\mathrm{K}$ and for a period of at least 120 days of storage in air. Using chemical vapor deposition to infiltrate the $250 \mathrm{~nm}$ pores of AAO scaffolds, Waleed and coworkers recently reported stabilization of $\alpha-\mathrm{CsPbI}_{3}$ at room temperature. ${ }^{153}$ In comparison, $\mathrm{CsPbI}_{3}$ deposited via spin coating in the same nanopores was found to adopt the orthorhombic $\gamma$ phase, indicating that processing conditions play a crucial role in determining final crystal structures. Nanoconfined stabilization of the metastable $\alpha$ phase of $\mathrm{FAPbI}_{3}$ from conversion to the thermodynamically stable $\delta$-phase at room temperature has also been reported ${ }^{154}$ although shifting of polymorph transitions temperatures was not reported.

\section{Influence of pressure on phase transitions}

Solid state phase transitions are a function of both temperature and pressure. Enabled by advances in synchrotron-based pressurized configurations for high-resolution diffraction measurements, ${ }^{155}$ pressured-induced phase transitions in MHPs have been intensely studied in recent years. Compared to other perovskites, MHPs exhibit high compressibility and pressure-dependent tunability of optoelectronic properties. ${ }^{156,157}$ Several reviews have already been published on pressure-induced phase transitions in MHPs and the role of pressure in modulating electronic landscapes, ${ }^{155,157-159}$ so we will only provide a brief overview here.

In general, MHPs undergo similar phase transitions upon pressurization in the range of atmospheric to $50 \mathrm{GPa}^{159}$ At lower pressures, structural changes are characterized by compression of $\mathrm{Pb}-\mathrm{I}$ bonds and/or octahedral tilting, as displayed in Fig. $10 .{ }^{160}$ At higher pressures, MHPs amorphize, a process which is reversible upon pressure reduction. $\mathrm{MAPbCl}_{3}$, for example, undergoes a cubic-to-cubic isostructural transition upon increasing the pressure from atmospheric pressure to 0.8 GPa due to a continuous decrease in the $\mathrm{Pb}-\mathrm{Cl}$ bond length. ${ }^{161}$ Increasing the pressure further to $2.4 \mathrm{GPa}$ was found to induce octahedral tilting such that the crystal structure transitions to an orthorhombic unit cell with Pnma symmetry. Fig. 11 summarizes the pressure-dependent phase behavior of 12 perovskites, including $\mathrm{CsPbCl}_{3},{ }^{162} \mathrm{CsPbBr}_{3},{ }^{163} \mathrm{CsPbI}_{3},{ }^{164} \mathrm{CsSnBr}_{3},{ }^{165}$ $\mathrm{MAPbCl}_{3},{ }^{161} \mathrm{MAPbBr}_{3},{ }^{166} \mathrm{MAPbI}_{3},{ }^{167} \mathrm{MASnCl}_{3},{ }^{161} \mathrm{MASnBr}_{3},{ }^{165}$ 

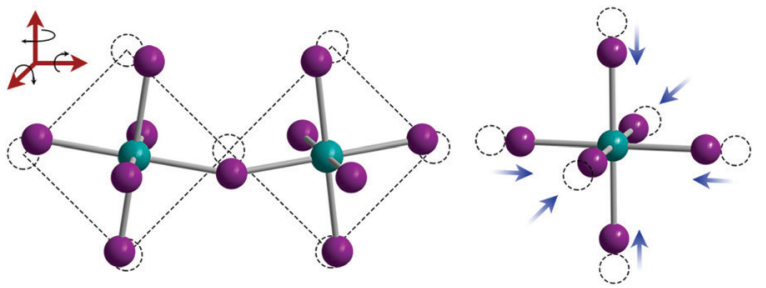

Fig. 10 Pressure-induced rotation of $\mathrm{Pbl}_{6}$ octahedra (left) and $\mathrm{Pb}-\mathrm{I}$ bond compression (right). Reproduced with permission from ref. 160. Copyright 2017, American Chemical Society.

$\mathrm{MASnI}_{3},{ }^{168} \mathrm{FAPbBr}_{3},{ }^{169}$ and $\mathrm{FAPbI}_{3} \cdot{ }^{170} \mathrm{CsPbCl}_{3}, \mathrm{CsPbBr}_{3}$ and $\mathrm{MaPbCl}_{3}$ all exhibit an isostructural phase transition in which the crystal symmetry is retained upon increasing pressure via symmetric compression of the $\mathrm{M}-\mathrm{X}$ bond. We note that there are some discrepancies in reported pressure-induced phase transitions, for example in widely studied $\mathrm{MAPbI}_{3},{ }^{167,171-174}$ which partially result from differing ambient pressure phase assignments.

In the opposite direction, lowering the pressure can also impact solid state phase transitions in MHPs. Decreasing the pressure to $10^{-3}$ mbar was recently found to shift the tetragonal to cubic phase transition temperature of $\mathrm{MAPbI}_{3}$ higher by $40{ }^{\circ} \mathrm{C}$, from $\sim 323-363 \mathrm{~K} .{ }^{175}$ Furthermore, the tetragonal and cubic phases were observed to coexist until a temperature of $140{ }^{\circ} \mathrm{C}$ was reached. This shift was attributed to a reduction in temperature-induced volume expansion rate of $\mathrm{MAPbI}_{3}$ upon pressure reduction.

Promisingly, recent reports have found that some pressureinduced changes can be retained upon cycling back to ambient pressure. For $\mathrm{FAPbI}_{3}$ exposed to pressures of $7.1 \mathrm{GPa}$, it was found that unit cell parameters at ambient pressure after compression were smaller compared to before compression, as evidenced by a shift in diffraction peaks to higher 2-theta values. ${ }^{176}$ This structural change resulted in a narrower bandgap of previously compressed versus uncompressed $\mathrm{FAPbI}_{3}$. Recently, quenching $\mathrm{MAPbI}_{3}$ from a high pressure state was found to result in retention of bandgap reduction upon pressurization. ${ }^{177}$ Partial retention of pressure-induced structural changes has also been reported for 2D perovskites. ${ }^{178,179}$

\section{Polymorph-dependent optoelectronic properties}

Among compounds adopting the $\mathrm{AMX}_{3}$ perovskite crystal structure, those incorporating halide ions in the $\mathrm{X}$ position have sufficiently small bandgaps, from $\sim 1.2-1.7 \mathrm{eV},{ }^{42}$ to absorb visible light and transport charge carriers for use in solar cells and other optoelectronic devices. First principle calculations have found that the bandgap is determined by the metal-halide framework, with A-site cations contributing minimally to the band structure. ${ }^{180,181}$ The valence band maximum comprises antibonding metal s and halogen p orbitals, while the conduction band minimum primarily comprises empty metal $p$ orbitals. ${ }^{181,182}$ The band structure of MHPs is sensitive to slight changes in the $\mathrm{M}-\mathrm{X}$ framework due to lattice contractions and octahedral tilting. ${ }^{183}$ Thus while not directly contributing to the band structure, A-site cations indirectly influence band structures through altering the $\mathrm{M}-\mathrm{X}$ framework.

These trends are exemplified in a recent comparison of the temperature-dependent optical bandgaps of $\mathrm{CsPbBr}_{3}, \mathrm{MAPbBr}_{3}$, and $\mathrm{FAPbBr}_{3}$ single crystals. ${ }^{184}$ As observed from Fig. 12, optical bandgaps decrease with increasing tolerance factors of 0.92, 1.04, and 1.14 for $\mathrm{CsPbBr}_{3}, \mathrm{MAPbBr}_{3}$, and $\mathrm{FaPbBr}_{3}$, respectively. ${ }^{15,185,186}$ Overall, the bandgaps of halide perovskites are strongly correlated to the $\mathrm{M}-\mathrm{X}-\mathrm{M}$ bond angle ${ }^{187,188}$ which can range from $150-180^{\circ}$, as described in detail in a 2015 account by Stoumpos and Kanatzidis. ${ }^{19}$ Upon bending, interactions between $\mathrm{M}$ p orbitals and $\mathrm{X}$ p antibonding orbitals increases, resulting in an increase of the bandgap. ${ }^{183}$ Significant efforts in the field have focused on exploiting the relationship between A-site cation size, the extent of $\mathrm{M}-\mathrm{X}-\mathrm{M}$ bond angle distortion, and the overall bandgap of the system through the engineering of mixed composition MHPs. ${ }^{189-195}$ For a series of $\operatorname{MAPb}\left(\mathrm{I}_{1-x} \mathrm{Br}_{x}\right)_{3}$ compounds, for example, Noh and coworkers reported the ability to continuously tune the bandgap from 1.6 to $2.3 \mathrm{eV}$ by increasing the value of $x$ from 0 to $1 .{ }^{196}$ Fig. 13 displays the bandgaps of six different MHPs as a function of the $\mathrm{X}-\mathrm{M}-\mathrm{X}$

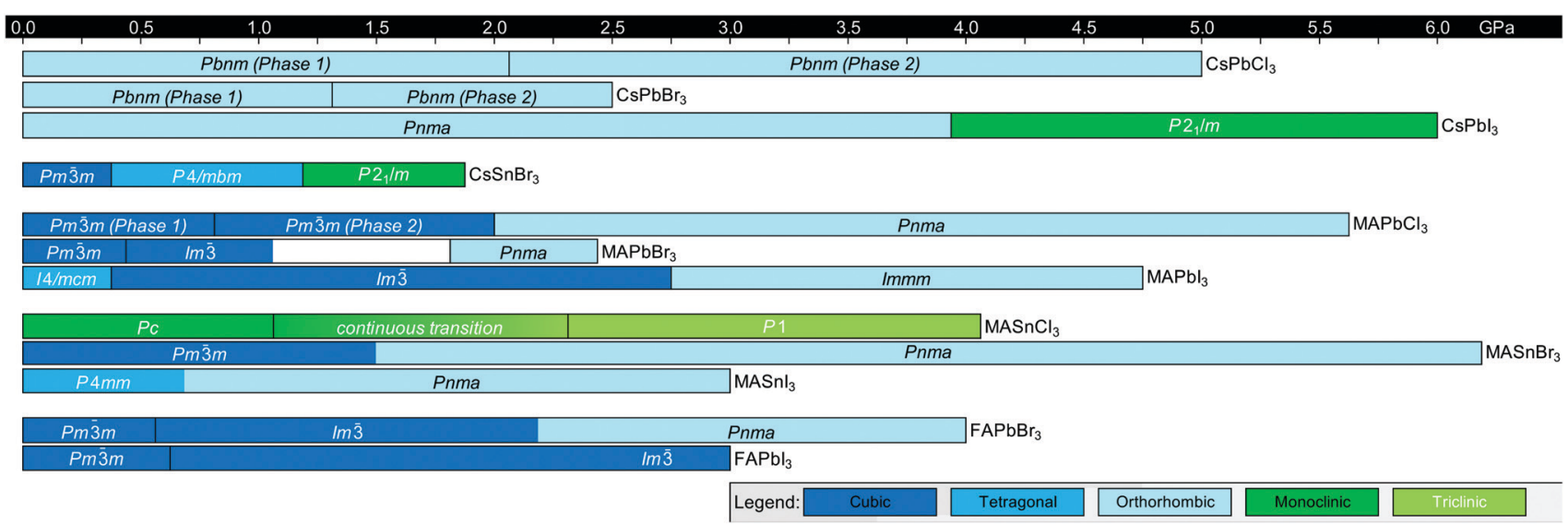

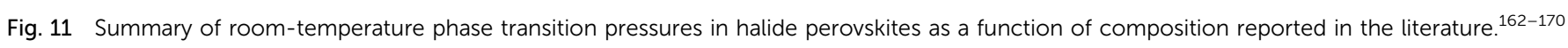
The white section in the data for $\mathrm{MAPbBr}_{3}$ indicates a region where data was not available. 


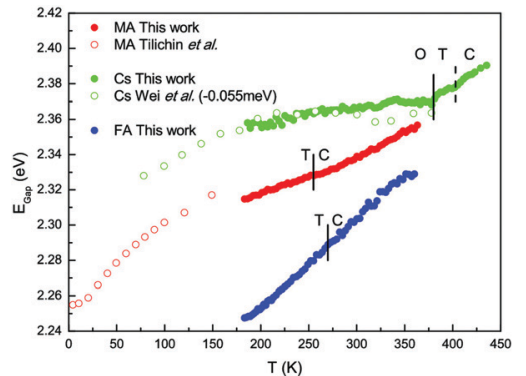

Fig. 12 Comparison of optical bandgap of $\mathrm{MAPbBr}_{3}, \mathrm{CsPbBr}_{3}$, and $\mathrm{FAPbBr}_{3}$ single crystals. Cubic, tetragonal and orthorhombic phases are indicated by $\mathrm{C}, \mathrm{T}$, and $\mathrm{O}$ labels, respectively. Reproduced with permission from ref. 184. Copyright 2020, American Chemical Society.

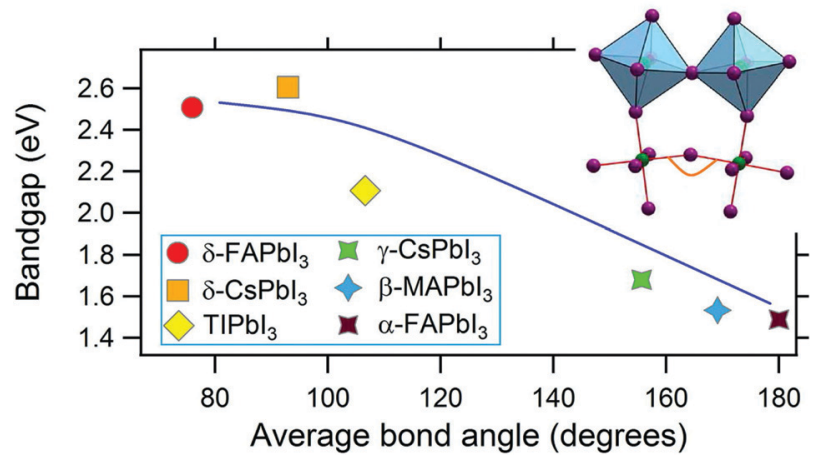

Fig. 13 Graph of the bandgap versus $M-X-M$ bond angle in MHPs Reproduced with permission from ref. 157. Copyright 2019, Elsevier.

bond angle. ${ }^{157}$ As observed from the figure, the bandgap decreases as this angle approaches $180^{\circ}$.

Following this trend of widening bandgaps with increased octahedral tilting among different MHP compounds, one might expect that within a single compound, the bandgap should decrease with increasing temperatures as MHPs transition from low-symmetry to high-symmetry structures. It has been demonstrated experimentally, however, that the bandgaps of MHPs increase with increasing temperature. ${ }^{197}$ Indeed, the temperature dependence of the optical bandgaps of $\mathrm{CsPBr}_{3}$, $\mathrm{MAPbBr}_{3}$, and $\mathrm{FAPbBr}_{3}$ in Fig. 12 all display a positive temperature coefficient, with monotonically increasing bandgaps with increasing temperature. For widely studied $\mathrm{MAPbI}_{3}$, a blue shift in the bandgap with increasing across the tetragonal-cubic transition has been recorded via temperature-dependent photoluminescence, ${ }^{198-203}$ spectroscopic ellipsometry, ${ }^{204}$ and vis-NIR absorption spectroscopy ${ }^{205}$ even though the nominal $\mathrm{Pb}-\mathrm{I}-\mathrm{Pb}$ angle increases from 165.3 to $180^{\circ}$ across the tetragonal-cubic transition.

Through a combination of temperature-dependent UV-vis absorption and ab initio simulations, Quarti and coworkers found that $\mathrm{MAPbI}_{3}$ monotonically blue-shifts through this transition due to large fluctuations in the $\mathrm{M}-\mathrm{X}$ framework on the picosecond time scale that increase with increasing temperature. $^{206}$ At temperatures above tetragonal-to-cubic phase transition, $\mathrm{MAPbI}_{3}$ was found to adopt the cubic structure on average, but in fact fluctuates between highly distorted configurations, resulting in an increase in the bandgap compared to the tetragonal phase. Computational modeling has attributed the increase in bandgap upon temperature increase to electron-phonon coupling and thermal expansion. ${ }^{197,207,208}$

Interestingly, we recently observed a $\sim 30 \mathrm{meV}$ red shift in the $\mathrm{PL}$ spectrum of $\mathrm{MAPbI}_{3}$ across the tetragonal-cubic transition when $\mathrm{MAPbI}_{3}$ crystals were nanoconfined in the $\sim 20-250$ diameter pores of AAO (Fig. 9), ${ }^{150}$ opposite of the trend observed in bulk crystals. By increasing the surface area-to-volume ratio of these crystals, nanoconfinement shifted the relative Gibbs free energies of the $\alpha, \beta$, and $\gamma$ phases such that the $\alpha-\beta$ transition temperature was lowered from $\sim 330 \mathrm{~K}$ to between $170-200 \mathrm{~K}$. At these lower temperatures, thermal fluctuations in the $\mathrm{M}-\mathrm{X}$ framework are likely suppressed, resulting in a narrowing of the bandgap upon transitioning to the cubic phase with I-Pb-I angles of $180^{\circ}$. This narrowing of the bandgap of $\alpha-\mathrm{MAPbI}_{3}$ compared to $\beta-\mathrm{MAPbI}_{3}$ is predicted when considering static structures. ${ }^{27,209,210}$

Examining pressure-induced changes in optoelectronic properties of MHPs has also advanced a fundamental understanding of the relationship between molecular structure and band structure. Pressure-induced compression of $\mathrm{M}-\mathrm{X}-\mathrm{M}$ bonds results in a decrease in the bandgap due to increased overlap between $\mathrm{Pb}$ 6s and I 5p orbitals, increasing the valence band energy and decreasing the overall bandgap. ${ }^{171,211} \mathrm{~A}$ linear positive correlation between $\mathrm{Pb}-\mathrm{I}-\mathrm{Pb}$ bond length and the bandgap, for example, has been reported for $\mathrm{MAPbI}_{3} .{ }^{172}$ On the other hand, octahedral tilting reduces this overlap, resulting in an increase in bandgap at higher pressures. ${ }^{159,167,172}$

Beyond the bandgap, the impact of polymorphic phase transitions on other optoelectronic properties varies for different compositions and temperature ranges. For $\mathrm{CsPbI}_{3}, \mathrm{CsSnI}_{3}$, and $\mathrm{FAPbI}_{3}$, polymorph transitions to their non-perovskite $\delta$-phases destroy device performance as these phases are insulating. For transitions between $\alpha, \beta$, and $\gamma$ phases, the impact on optoelectronic properties is less catastrophic, but can be detrimental nonetheless. While many questions still remain about optoelectronic processes in these materials, ${ }^{212,213}$ recent temperaturedependent studies have begun to track photophysical processes across polymorph transitions, particularly in widely studied $\mathrm{MAPbI}_{3}$.

In 2015, for example, Milot and coworkers used temperaturedependent time-resolved PL and THz conductivity measurements to examine charge recombination in $\mathrm{MAPbI}_{3} .{ }^{11}$ The rate of monomolecular recombination was observed to increase smoothly in the range of $8-340 \mathrm{~K}$. On the other hand, the temperature dependence of bimolecular and Auger recombination rates were found to depend on the polymorph, as displayed in Fig. 14. In particular, Auger recombination rates significantly increased upon transition from the tetragonal to orthorhombic phase. In a later study, pulse-radiolysis time-resolved microwave conductivity experiments on $\mathrm{MAPbI}_{3}$ and $\mathrm{MAPbBr}_{3}$ further revealed abrupt increases in charge carrier mobilities and lifetimes when crystals transitioned from the tetragonal to the orthorhombic phase. ${ }^{214}$ While $\mathrm{MA}^{+}$cations can rotate in the tetragonal phase, their orientation becomes fixed in the orthorhombic phase to form 
A
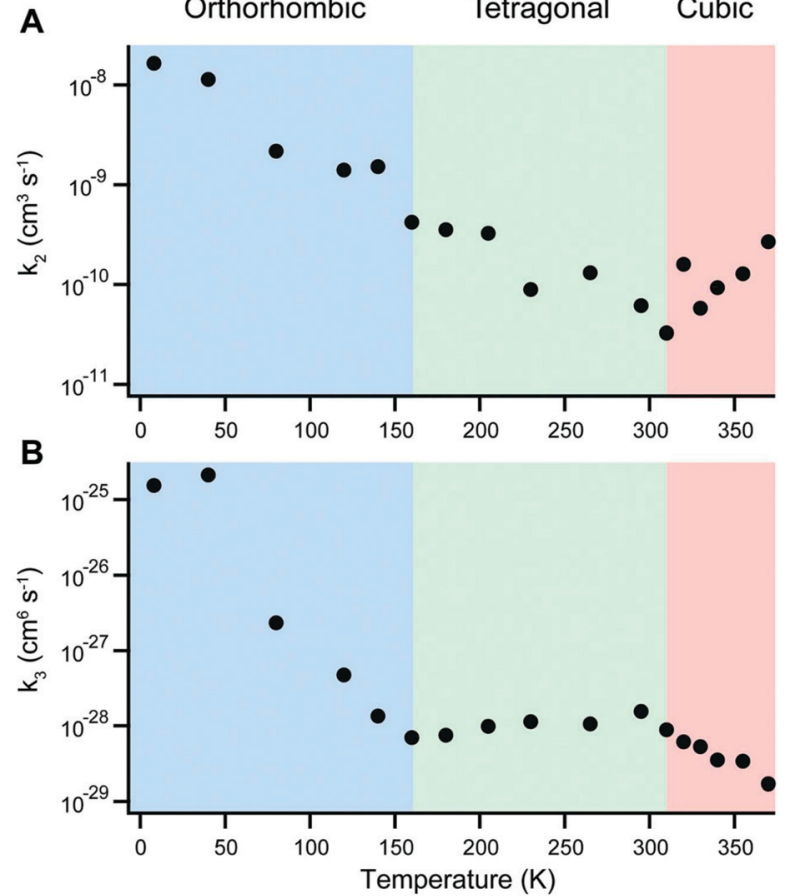

Fig. 14 Temperature dependence of (A) bimolecular and (B) Auger recombination rates for $\mathrm{MAPbl}_{3}$. Reproduced with permission from ref. 11. Copyright 2015, Wiley.

charged domains that reduce charge recombination. This ordering of the $\mathrm{MA}^{+}$cation was found to result in smaller dielectric constants and larger exciton binding energies compared to the tetragonal phase, contributing to a faster rate of ground state bleaching recovery in the former phase. ${ }^{215}$ In contrast, no abrupt changes across the tetragonal-orthorhombic phase transition for $\mathrm{FAPbI}_{3}$ was observed due to the fact that $\mathrm{FA}^{+}$retain rotational freedom in the low-temperature orthorhombic phase. ${ }^{216}$

Because the $\mathrm{MA}^{+}$cations can rotate in all directions in both the tetragonal and cubic phases of $\mathrm{MAPbI}_{3}$, their role in modulating photophysical processes across the tetragonalcubic transition may be less pronounced compared to the orthorhombic-tetragonal transition. Examining temperaturedependent dielectric properties of $\mathrm{MAPbI}_{3}$ using microwave conductance experiments found that cation rotation was too slow to influence charge carrier mobilities and lifetimes in the range of $160-300 \mathrm{~K}^{217}$ Recent temperature-dependent photoconductivity experiments on $\mathrm{FAPBBr}_{3}$, on the other hand, revealed multiple discontinuities in the peak intensities and peak locations, only two of which corresponded to crystallographic phase changes from the cubic to tetragonal phase at $266 \mathrm{~K}$ and the tetragonal to orthorhombic phase at $153 \mathrm{~K}^{218}$ Fig. 15 displays the photoconductivity characteristics, heat capacity, and mean square displacement (MSD) of hydrogen atoms as a function of temperature. Five distinct discontinuities can be observed in the temperature-dependent excitonic peak center, represented by gray circles in Fig. 15a. These five transitions were all found to correspond to discontinuities in the temperature-dependent MSD of hydrogen, as measured by

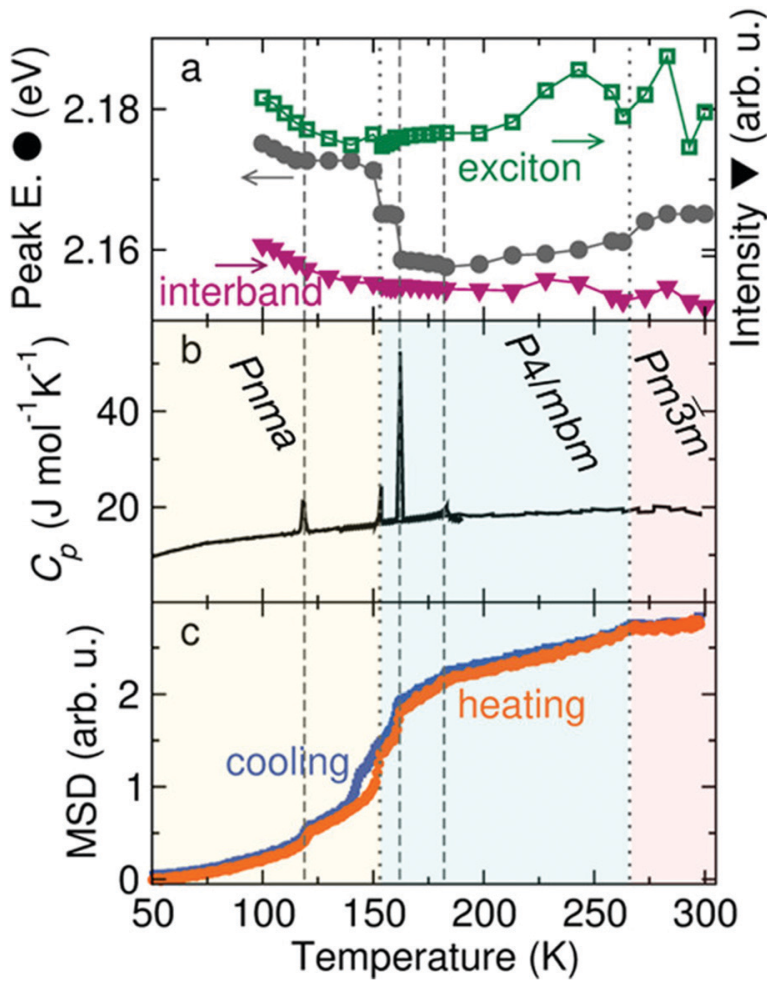

Fig. 15 (a) Plot of the excitonic peak intensity (green squares), excitonic peak center (gray circles) and interband intensity (purple triangles) extracted from photoconductivity data as a function of excitation wavelength and temperature for $\mathrm{FAPbBr}_{3}$. (b) Differential scanning calorimetry scan for $\mathrm{FAPbBr}_{3}$, with crystallographic phases at different temperatures labelled. (c) Mean squared displacement of hydrogen upon heating and cooling of $\mathrm{FAPbBr}_{3}$ measured via elastic neutron scattering. Dotted and dashed lines represent discontinuities in the spectra that do and do not correspond to solid-state phase transitions, respectively. Reproduced with permission from ref. 218. Copyright 2019, American Chemical Society.

elastic neutron scattering (Fig. 15c). These results suggest that $\mathrm{FA}^{+}$rotational dynamics may induce local temperaturedependent distortions through dynamic coupling to the $\mathrm{M}-\mathrm{X}$ framework.

One of the main applications for MHPs is in emerging photovoltaics to harvest renewable solar energy. Depending on the location and specific use, solar panels can be exposed to a wide range of temperatures, inducing polymorph transitions in the MHP active layer during device operation. Monitoring structural phase transitions in $\mathrm{MAPbI}_{3}$ active layers during solar cell operation, Zhang and coworkers observed a drop in photocurrent from $20 \mathrm{~mA} \mathrm{~cm}{ }^{-2}$ at $240 \mathrm{~K}$ to $1 \mathrm{~mA} \mathrm{~cm}^{-2}$ at $140 \mathrm{~K}^{219}$ This large difference in photocurrent was attributed to a phase transition from the tetragonal to orthorhombic phase upon lowering the temperature. In these devices, power conversion efficiencies of $<0.1 \%$ were measured at temperatures below $160 \mathrm{~K}$ when the orthorhombic phase was present, compared to a maximum efficiency of $16 \%$ at $300 \mathrm{~K}$ for tetragonal $\mathrm{MAPbI}_{3}{ }^{219}$ Recent time-of-flight and electrical conductivity measurements on $\mathrm{MAPbI}_{3}$ solar cells have further revealed a balancing of electron and hole mobilities at the tetragonal-cubic phase transition. ${ }^{20}$ 


\section{Conclusion}

The chemical diversity and flexibility of MHPs has given rise to myriad possibilities of structures and compositions for use in optoelectronic devices. Systematic experimental and computational studies of the relationships between A-site, M-site and $\mathrm{X}$-site ion sizes and the crystal structure of MHPs, as well as temperature-dependent measurements of these crystals via high-resolution X-ray and neutron diffraction, have provided a comprehensive understanding of the factors governing polymorphism in this class of materials. In general, MHPs with tolerance factors closer to 1 will adopt a cubic structure at room temperature, whereas octahedral tilting in MHPs with tolerance factors farther from 1 result in orthorhombic or tetragonal crystal structures under ambient conditions. MHPs transition from lower to higher symmetry with increasing temperature, but higher to lower symmetry with increasing pressure. More complex and less understood are how slight changes in bond lengths and angles, as well as A-site cation dynamics, affect the electronic structure and optoelectronic processes, such as exciton recombination and charge transport. Looking forward, optoelectronic characterization across phase transitions will provide further mechanistic insights into the interplay between charges and the metal halide framework. The role of strategies to shift solid-state phase transition temperatures, for example via size reduction or nanoconfinement, and to kinetically trap metastable phases, such as through pressure cycling, have the potential to improve both the performance and reliability of MHP-based devices. Looking towards future commercialization, suppression of polymorph transitions that negatively impact device performance will be necessary, and research on structure-property-function relationships across these solid-state transitions will undoubtedly play a critical role in the advancement of MHPs for optoelectronic applications.

\section{Conflicts of interest}

There are no conflicts to declare.

\section{Acknowledgements}

The authors acknowledge support from the National Science Foundation under Award No. CMMI-AM-1846178. The authors are also grateful for support from the PSEG Foundation to advance energy innovation at Stevens.

\section{References}

1 NREL, Best Res. Effic. Chart / Photovolt. Res. / NREL, 2020, https://www.nrel.gov/pv/cell-efficiency.html.

2 J. Yan and B. R. Saunders, RSC Adv., 2014, 4, 43286-43314. 3 K. X. Steirer, P. Schulz, G. Teeter, V. Stevanovic, M. Yang, K. Zhu and J. J. Berry, ACS Energy Lett., 2016, 1, 360-366.

4 J. Kang and L. W. Wang, J. Phys. Chem. Lett., 2017, 8, 489-493.
5 J. A. Steele, H. Jin, I. Dovgaliuk, R. F. Berger, T. Braeckevelt, H. Yuan, C. Martin, E. Solano, K. Lejaeghere, S. M. J. Rogge, C. Notebaert, W. Vandezande, K. P. F. Janssen, B. Goderis, E. Debroye, Y. K. Wang, Y. Dong, D. Ma, M. Saidaminov, H. Tan, Z. Lu, V. Dyadkin, D. Chernyshov, V. Van Speybroeck, E. H. Sargent, J. Hofkens and M. B. J. Roeffaers, Science, 2019, 365, 679-684.

6 D. H. Fabini, C. C. Stoumpos, G. Laurita, A. Kaltzoglou, A. G. Kontos, P. Falaras, M. G. Kanatzidis and R. Seshadri, Angew. Chem., Int. Ed., 2016, 55, 15392-15396.

7 E. L. Da Silva, J. M. Skelton, S. C. Parker and A. Walsh, Phys. Rev. B: Condens. Matter Mater. Phys., 2015, 91, 144107.

8 S. Masi, A. F. Gualdrón Reyes and I. Mora-Seró, ACS Energy Lett., 2020, 5, 1974-1985.

9 J. Shi, Y. Wang and Y. Zhao, Energy Environ. Mater., 2019, 2, 73-78.

10 Y. Fan, H. Meng, L. Wang and S. Pang, Sol. RRL, 2019, 3, 1900215.

11 R. L. Milot, G. E. Eperon, H. J. Snaith, M. B. Johnston and L. M. Herz, Adv. Funct. Mater., 2015, 25, 6218-6227.

12 J. S. Bechtel and A. Van Der Ven, Phys. Rev. Mater., 2018, 2, 025401.

13 V. M. Goldschmidt, Naturwissenschaften, 1926, 14, 477-485.

14 L. Q. Jiang, J. K. Guo, H. B. Liu, M. Zhu, X. Zhou, P. Wu and C. H. Li, J. Phys. Chem. Solids, 2006, 67, 1531-1536.

15 W. Travis, E. N. K. Glover, H. Bronstein, D. O. Scanlon and R. G. Palgrave, Chem. Sci., 2016, 7, 4548-4556.

16 C. Li, X. Lu, W. Ding, L. Feng, Y. Gao and Z. Guo, Acta Crystallogr., Sect. B: Struct. Sci., 2008, 64, 702-707.

17 A. M. Glazer, Acta Crystallogr., Sect. B: Struct. Crystallogr. Cryst. Chem., 1972, B28, 3384-3392.

18 J. Even, M. Carignano and C. Katan, Nanoscale, 2016, 8, 6222.

19 C. C. Stoumpos and M. G. Kanatzidis, Acc. Chem. Res., 2015, 48, 2791-2802.

20 Y. Fujii, S. Hoshino, Y. Yamada and G. Shirane, Phys. Rev. B: Solid State, 1974, 9, 4549-4559.

21 S. Hirotsu and S. Sawada, Phys. Lett. A, 1969, 28, 762-763.

22 S. Plesko, R. Kind and J. Roos, J. Phys. Soc. Jpn., 1978, 45, 553-557.

23 C. Carabatos-Nédelec, M. Oussaïd and K. Nitsch, J. Raman Spectrosc., 2003, 34, 388-393.

24 C. C. Stoumpos, C. D. Malliakas, J. A. Peters, Z. Liu, M. Sebastian, J. Im, T. C. Chasapis, A. C. Wibowo, D. Young Chung, A. J. Freeman, B. W. Wessels and M. G. Kanatzidis, Cryst. Growth Des., 2013, 13, 2722-2727.

25 S. Hirotsu, T. Suzuki and S. Sawada, J. Phys. Soc. Jpn., 1977, 43, 575-582.

26 M. Rodová, J. Brožek, K. Knížek, K. Nitsch, J. Brooek, K. Knííek and K. Nitsch, J. Therm. Anal. Calorim., 2003, 71, 667-673.

27 A. Marronnier, G. Roma, S. Boyer-Richard, L. Pedesseau, J. M. Jancu, Y. Bonnassieux, C. Katan, C. C. Stoumpos, M. G. Kanatzidis and J. Even, ACS Nano, 2018, 12, 3477-3486.

28 R. J. Sutton, M. R. Filip, A. A. Haghighirad, N. Sakai, B. Wenger, F. Giustino and H. J. Snaith, ACS Energy Lett., 2018, 3, 1787-1794. 
29 D. E. Scaife, P. F. Weller and W. G. Fisher, J. Solid State Chem., 1974, 9, 308-314.

30 K. Yamada, Y. Kuranaga, K. Ueda, S. Goto, T. Okuda and Y. Furukawa, Bull. Chem. Soc. Jpn., 1998, 71, 127-134.

31 D. H. Fabini, G. Laurita, J. S. Bechtel, C. C. Stoumpos, H. A. Evans, A. G. Kontos, Y. S. Raptis, P. Falaras, A. Van Der Ven, M. G. Kanatzidis and R. Seshadri, J. Am. Chem. Soc., 2016, 138, 11820-11832.

32 R. H. Andrews, J. D. Donaldson, J. Silver and E. A. D. White, J. Mater. Sci., 1975, 10, 1449-1451.

33 K. Yamada, S. Funabiki, H. Horimoto, T. Matsui, T. Okuda and S. Ichiba, Chem. Lett., 1991, 801-804.

34 I. Chung, J. H. Song, J. Im, J. Androulakis, C. D. Malliakas, H. Li, A. J. Freeman, J. T. Kenney and M. G. Kanatzidis, J. Am. Chem. Soc., 2012, 134, 8579-8587.

35 L. Chi, I. Swainson, L. Cranswick, J. H. Her, P. Stephens and O. Knop, J. Solid State Chem., 2005, 178, 1376-1385.

36 A. Poglitsch and D. Weber, J. Chem. Phys., 1987, 87, 6373-6378.

37 A. Bernasconi, K. Page, Z. Dai, L. Z. Tan, A. M. Rappe and L. Malavasi, J. Phys. Chem. C, 2018, 122, 28265-28272.

38 W. M. I. P. Swainson, R. P. Hammond, C. Soulliere and O. Knop, J. Solid State Chem., 2003, 176, 97-104.

39 T. Baikie, N. S. Barrow, Y. Fang, P. J. Keenan, P. R. Slater, R. O. Piltz, M. Gutmann, S. G. Mhaisalkar and T. J. White, J. Mater. Chem. A, 2015, 3, 9298-9307.

40 N. Onoda-Yamamuro, O. Yamamuro, T. Matsuo and H. Suga, J. Phys. Chem. Solids, 1992, 53, 277-281.

41 T. Baikie, Y. Fang, J. M. Kadro, M. Schreyer, F. Wei, S. G. Mhaisalkar, M. Graetzel and T. J. White, J. Mater. Chem. A, 2013, 1, 5628.

42 C. C. Stoumpos, C. D. Malliakas and M. G. Kanatzidis, Inorg. Chem., 2013, 52, 9019-9938.

43 M. T. Weller, O. J. Weber, P. F. Henry, A. M. Di Pumpo and T. C. Hansen, Chem. Commun., 2015, 51, 4180-4183.

44 Y. Takahashi, R. Obara, Z.-Z. Lin, Y. Takahashi, T. Naito, T. Inabe, S. Ishibashi and K. Terakura, Dalton Trans., 2011, 40, 5563.

45 Y. Takahashi, H. Hasegawa, Y. Takahashi and T. Inabe, J. Solid State Chem., 2013, 205, 39-43.

46 S. Govinda, B. P. Kore, D. Swain, A. Hossain, C. De, T. N. Guru Row and D. D. Sarma, J. Phys. Chem. C, 2018, 122, 13758-13766.

47 E. C. Schueller, G. Laurita, D. H. Fabini, C. C. Stoumpos, M. G. Kanatzidis and R. Seshadri, Inorg. Chem., 2018, 57, 695-701.

48 C. Ferrara, M. Patrini, A. Pisanu, P. Quadrelli, C. Milanese, C. Tealdi and L. Malavasi, J. Mater. Chem. A, 2017, 5, 9391-9395.

49 M. R. Filip, G. E. Eperon, H. J. Snaith and F. Giustino, Nat. Commun., 2014, 5, 5757.

50 G. Kieslich, S. Sun and A. K. Cheetham, Chem. Sci., 2014, 5, 4712-4715.

51 J. Gebhardt and A. M. Rappe, Adv. Mater., 2019, 31, 1-15.

52 I. P. Swainson, R. P. Hammond, C. Soullière, O. Knop and W. Massa, J. Solid State Chem., 2003, 176, 97-104.
53 C. A. López, M. V. Martínez-Huerta, M. C. Alvarez-Galván, P. Kayser, P. Gant, A. Castellanos-Gomez, M. T. FernándezDíaz, F. Fauth and J. A. Alonso, Inorg. Chem., 2017, 56, 14214-14219.

54 W. Xiang and W. Tress, Adv. Mater., 2019, 31, 1902851.

55 C. K. Moller, Mat. Fys. Medd. Dan. Vid. Sels., 1959, 32, 1.

56 Y. Fujii, S. Hoshino, Y. Yamada and G. Shirane, Phys. Rev. B: Solid State, 1974, 9, 4549-4559.

57 T. Sakudo, H. Unoki, Y. Fujii, J. Kobayashi and M. Yamada, Phys. Lett. A, 1969, 28, 542-543.

58 N. Yantara, S. Bhaumik, F. Yan, D. Sabba, H. A. Dewi, N. Mathews, P. P. Boix, H. V. Demir and S. Mhaisalkar, J. Phys. Chem. Lett., 2015, 6, 4360-4364.

59 G. E. Eperon, G. M. Paternò, R. J. Sutton, A. Zampetti, A. A. Haghighirad, F. Cacialli and H. J. Snaith, J. Mater. Chem. A, 2015, 3, 19688-19695.

60 J. Liang, J. Liu and Z. Jin, Sol. RRL, 2017, 1, 1700086.

61 X. Li, F. Cao, D. Yu, J. Chen, Z. Sun, Y. Shen, Y. Zhu, L. Wang, Y. Wei, Y. Wu and H. Zeng, Small, 2017, 13.

62 P. Ramasamy, D. H. Lim, B. Kim, S. H. Lee, M. S. Lee and J. S. Lee, Chem. Commun., 2016, 52, 2067-2070.

63 C. Li, C. Han, Y. Zhang, Z. Zang, M. Wang, X. Tang and J. Du, Sol. Energy Mater. Sol. Cells, 2017, 172, 341-346.

64 K. P. Marshall, M. Walker, R. I. Walton and R. A. Hatton, Nat. Energy, 2016, 1, 1-9.

65 T. Bin Song, T. Yokoyama, C. C. Stoumpos, J. Logsdon, D. H. Cao, M. R. Wasielewski, S. Aramaki and M. G. Kanatzidis, J. Am. Chem. Soc., 2017, 139, 836-842.

66 C. Huo, X. Liu, X. Song, Z. Wang and H. Zeng, J. Phys. Chem. Lett., 2017, 8, 4785-4792.

67 S. Zhou, G. Zhou, Y. Li, X. Xu, Y.-J. Hsu, J. Xu, N. Zhao and X. Lu, ACS Energy Lett., 2020, 23, 2614-2623.

68 H. Cho, C. Wolf, J. S. Kim, H. J. Yun, J. S. Bae, H. Kim, J.-M. Heo, S. Ahn and T.-W. Lee, Adv. Mater., 2017, 29, 1700579.

69 Z. Shi, S. Li, Y. Li, H. Ji, X. Li, D. Wu, T. Xu, Y. Chen, Y. Tian, Y. Zhang, C. Shan and G. Du, ACS Nano, 2018, 12, 1462-1472.

70 C. Wu, Y. Zou, T. Wu, M. Ban, V. Pecunia, Y. Han, Q. Liu, T. Song, S. Duhm and B. Sun, Adv. Funct. Mater., 2017, 27, 1700338.

71 Y. Wang, X. Liu, T. Zhang, X. Wang, M. Kan, J. Shi and Y. Zhao, Angew. Chem. Int. Ed., 2019, 58, 16691-16696.

72 S. Tao, I. Schmidt, G. Brocks, J. Jiang, I. Tranca, K. Meerholz and S. Olthof, Nat. Commun., 2019, 10, 1-10.

73 P. Mauersberger and F. Huber, Acta Crystallogr., Sect. B: Struct. Crystallogr. Cryst. Chem., 1980, 36, 683-684.

74 R. J. Sutton, G. E. Eperon, L. Miranda, E. S. Parrott, B. A. Kamino, J. B. Patel, M. T. Hörantner, M. B. Johnston, A. A. Haghighirad, D. T. Moore and H. J. Snaith, Adv. Energy Mater., 2016, 6, 1502458.

75 K. Yamada, S. Funabiki, H. Horimoto, T. Matsui, T. Okuda and S. Ichiba, Chem. Lett., 1991, 801-804.

76 A. Kojima, K. Teshima, Y. Shirai and T. Miyasaka, J. Am. Chem. Soc., 2009, 131, 6050-6051.

77 C.-Y. Chen, H.-Y. Lin, K.-M. Chiang, W.-L. Tsai, Y.-C. Huang, C.-S. Tsao and H.-W. Lin, Adv. Mater., 2017, 29, 1605290. 
78 Y. Yang, J. P. Robbins, L. Ezeonu, Y. Ma, N. Sparta, X. Kong, S. Strauf, S. G. Podkolzin and S. S. Lee, J. Mater. Chem. C, 2020, 8, 8896-8903.

79 Z. Xiao and Y. Yan, Adv. Energy Mater., 2017, 7, 1701136.

80 P. S. Whitfield, N. Herron, W. E. Guise, K. Page, Y. Q. Cheng, I. Milas and M. K. Crawford, Sci. Rep., 2016, 6, 35685 .

81 C. Motta, F. El-Mellouhi, S. Kais, N. Tabet, F. Alharbi and S. Sanvito, Nat. Commun., 2015, 6, 1-7.

82 D. Weber, Z. Naturforsch. B, 1978, 33, 1443-1445.

83 A. Poglitsch and D. Weber, J. Chem. Phys., 1987, 87, 6373-6378.

84 N. Onoda-Yamamuro, T. Matsuo and H. Suga, J. Phys. Chem. Solids, 1990, 51, 1383-1395.

85 D. H. Fabini, T. Hogan, H. A. Evans, C. C. Stoumpos, M. G. Kanatzidis and R. Seshadri, J. Phys. Chem. Lett., 2016, 7, 376-381.

86 D. H. Fabini, C. C. Stoumpos, G. Laurita, A. Kaltzoglou, A. G. Kontos, P. Falaras, M. G. Kanatzidis and R. Seshadri, Angew. Chem. Int. Ed., 2016, 55, 15392-15396.

87 I. Anusca, S. Balčiūnas, P. Gemeiner, Š. Svirskas, M. Sanlialp, G. Lackner, C. Fettkenhauer, J. Belovickis, V. Samulionis, M. Ivanov, B. Dkhil, J. Banys, V. V. Shvartsman and D. C. Lupascu, Adv. Energy Mater., 2017, 7, 1700600.

88 J. H. Lee, J. H. Lee, E. H. Kong and H. M. Jang, Sci. Rep., 2016, 6, 305-353.

89 J. H. Lee, N. C. Bristowe, J. H. Lee, S. H. Lee, P. D. Bristowe, A. K. Cheetham and H. M. Jang, Chem. Mater., 2016, 28, 4259-4266.

90 J. S. Bechtel, R. Seshadri and A. Van Der Ven, J. Phys. Chem. C, 2016, 120, 12403-12410.

91 M. A. Carignano, Y. Saeed, S. A. Aravindh, I. S. Roqan, J. Even and C. Katan, Phys. Chem. Chem. Phys., 2016, 18, 27109-27118.

92 J. Even, M. Carignano and C. Katan, Nanoscale, 2016, 8, 6222-6236.

93 I. P. Swainson, C. Stock, S. F. Parker, L. Van Eijck, M. Russina and J. W. Taylor, Phys. Rev. B: Condens. Matter Mater. Phys., 2015, 92, 100303.

94 T. Chen, B. J. Foley, B. Ipek, M. Tyagi, J. R. D. Copley, C. M. Brown, J. J. Choi and S.-H. Lee, Phys. Chem. Chem. Phys., 2015, 17, 31278-31286.

95 A. M. A. Leguy, J. M. Frost, A. P. McMahon, V. G. Sakai, W. Kockelmann, C. Law, X. Li, F. Foglia, A. Walsh, B. C. O'Regan, J. Nelson, J. T. Cabral and P. R. F. Barnes, Nat. Commun., 2015, 6, 7124.

96 K. Druzbicki, R. S. Pinna, S. Rudić, M. Jura, G. Gorini and F. Fernandez-Alonso, J. Phys. Chem. Lett., 2016, 7, 4701-4709.

97 B. Li, Y. Kawakita, Y. Liu, M. Wang, M. Matsuura, K. Shibata, S. Ohira-Kawamura, T. Yamada, S. Lin, K. Nakajima and S. F. Liu, Nat. Commun., 2017, 8, 1-9.

98 W. M. J. Franssen, S. G. D. Van Es, R. Dervişoğlu, G. A. De Wijs and A. P. M. Kentgens, J. Phys. Chem. Lett., 2017, 8, 61-66.
99 C. Roiland, G. Trippé-Allard, K. Jemli, B. Alonso, J. C. Ameline, R. Gautier, T. Bataille, L. Le Pollès, E. Deleporte, J. Even and C. Katan, Phys. Chem. Chem. Phys., 2016, 18, 27133-27142.

100 B. A. Rosales, L. Men, S. D. Cady, M. P. Hanrahan, A. J. Rossini and J. Vela, Chem. Mater., 2016, 28, 6848-6859.

101 S. Govinda, B. P. Kore, D. Swain, A. Hossain, C. De, T. N. Guru Row and D. D. Sarma, J. Phys. Chem. C, 2018, 122, 42.

102 A. A. Bakulin, O. Selig, H. J. Bakker, Y. L. A. Rezus, C. Müller, T. Glaser, R. Lovrincic, Z. Sun, Z. Chen, A. Walsh, J. M. Frost and T. L. C. Jansen, J. Phys. Chem. Lett., 2015, 6, 3663-3669.

103 J. Gong, M. Yang, X. Ma, R. D. Schaller, G. Liu, L. Kong, Y. Yang, M. C. Beard, M. Lesslie, Y. Dai, B. Huang, K. Zhu and T. Xu, J. Phys. Chem. Lett., 2016, 7, 2879-2887.

104 Y. Guo, O. Yaffe, D. W. Paley, A. N. Beecher, T. D. Hull, G. Szpak, J. S. Owen, L. E. Brus and M. A. Pimenta, Phys. Rev. Mater., 2017, 1, 042401.

105 R. E. Wasylishen, O. Knop and J. B. Macdonald, Solid State Commun., 1985, 56, 581-582.

106 B. J. Foley, B. Ipek, M. Tyagi, J. R. D. Copley, C. M. Brown, J. J. Choi, S.-H. H. Lee, T. Chen, B. J. Foley, B. Ipek, M. Tyagi, J. R. D. Copley, C. M. Brown, J. J. Choi, S.-H. H. Lee, J. R. D. Copley, C. M. Brown, J. J. Choi and S.-H. H. Lee, Phys. Chem. Chem. Phys., 2015, 17, 31278-31286.

107 D. H. Fabini, Ting, A. Siaw, C. C. Stoumpos, G. Laurita, D. Olds, K. Page, J. G. Hu, M. G. Kanatzidis, S. Han and R. Seshadri, DOI: 10.1021/jacs.7b09536.

108 Y. Ren, I. W. H. Oswald, X. Wang, G. T. McCandless and J. Y. Chan, Cryst. Growth Des., 2016, 16, 2945-2951.

109 J. Breternitz, M. Tovar and S. Schorr, Sci. Rep., 2020, 10, 16613.

110 M. Szafrański and A. Katrusiak, J. Phys. Chem. Lett., 2016, 7, 3458-3466.

111 C. C. Stoumpos, C. D. Malliakas and M. G. Kanatzidis, Inorg. Chem., 2013, 52, 9019-9038.

112 Y. Rakita, O. Bar-Elli, E. Meirzadeh, H. Kaslasi, Y. Peleg, G. Hodes, I. Lubomirsky, D. Oron, D. Ehre and D. Cahen, Proc. Natl. Acad. Sci. U. S. A., 2017, 114, E5504-E5512.

113 K. Frohna, T. Deshpande, J. Harter, W. Peng, B. A. Barker, J. B. Neaton, S. G. Louie, O. M. Bakr, D. Hsieh and M. Bernardi, Nat. Commun., 2018, 9, 1-9.

114 R. Ohmann, L. K. Ono, H. S. Kim, H. Lin, M. V. Lee, Y. Li, N. G. Park and Y. Qi, J. Am. Chem. Soc., 2015, 137, 16049-16054.

115 A. Mattoni, A. Filippetti, M. I. Saba and P. Delugas, J. Phys. Chem. C, 2015, 119, 17421-17428.

116 J.-H. Lee, N. C. Bristowe, P. D. Bristowe and A. K. Cheetham, Chem. Commun., 2015, 51, 6434.

117 J. Li, M. Bouchard, P. Reiss, D. Aldakov, S. Pouget, R. Demadrille, C. Aumaitre, B. Frick, D. Djurado, M. Rossi and P. Rinke, J. Phys. Chem. Lett., 2018, 9, 3969-3977.

118 G. Schuck, D. M. Többens, M. Koch-Müller, I. Efthimiopoulos and S. Schorr, J. Phys. Chem. C, 2018, 122, 5227-5237.

119 F. Brivio, J. M. Frost, J. M. Skelton, A. J. Jackson, O. J. Weber, M. T. Weller, A. R. Goñi, A. M. A. Leguy, 
P. R. F. Barnes and A. Walsh, Phys. Rev. B: Condens. Matter Mater. Phys., 2015, 92, 144308.

120 I. Deretzis and A. La Magna, Nanoscale, 2017, 9, 5896-5903. 121 S. Maheshwari, M. B. Fridriksson, S. Seal, J. Meyer and F. C. Grozema, J. Phys. Chem. C, 2019, 123, 14652-14661.

122 S. Kanno, Y. Imamura, A. Saeki and M. Hada, J. Phys. Chem. C, 2017, 121, 14051-14059.

123 O. J. Weber, D. Ghosh, S. Gaines, P. F. Henry, A. B. Walker, M. S. Islam and M. T. Weller, Chem. Mater., 2018, 30, 3768-3778.

124 Y. Li, F. Z. Liu, M. Waqas, T. L. Leung, H. W. Tam, X. Q. Lan, B. Tu, W. Chen, A. B. Djurišić and Z. B. He, Small Methods, 2018, 2, 1700387.

125 W. S. Yang, B. W. Park, E. H. Jung, N. J. Jeon, Y. C. Kim, D. U. Lee, S. S. Shin, J. Seo, E. K. Kim, J. H. Noh and S. Il Seok, Science, 2017, 356, 1376-1379.

126 E. Smecca, Y. Numata, I. Deretzis, G. Pellegrino, S. Boninelli, T. Miyasaka, A. La Magna and A. Alberti, Phys. Chem. Chem. Phys., 2016, 18, 13413-13422.

127 O. J. Weber, D. Ghosh, S. Gaines, P. F. Henry, A. B. Walker, M. S. Islam and M. T. Weller, Chem. Mater., 2018, 30, 3768-3778.

128 A. Franz, D. M. Többens, F. Lehmann, M. Kärgell and S. Schorr, Res. Pap. Acta Crystallogr., 2020, 76, 267-274.

129 D. H. Fabini, T. A. Siaw, C. C. Stoumpos, G. Laurita, D. Olds, K. Page, J. G. Hu, M. G. Kanatzidis, S. Han and R. Seshadri, J. Am. Chem. Soc., 2017, 139, 16875-16884.

130 X. Kong, K. Zong and S. S. Lee, Chem. Mater., 2019, 31, 4953-4970.

131 G. T. Rengarajan, D. Enke, M. Steinhart and M. Beiner, Phys. Chem. Chem. Phys., 2011, 13, 21367-21374.

132 J. M. McHale, A. Auroux, A. J. Perrotta and A. Navrotsky, Science, 1997, 277, 788-789.

133 R. C. Garvie, J. Phys. Chem., 1978, 82, 218-224.

134 D. Fu and H. Suzuki, Phys. Rev. B: Condens. Matter Mater. Phys., 2000, 62, 3125-3129.

135 P. Ayyub, S. Chattopadhyay, M. Multani and B. Road, Phys. Rev. B: Condens. Matter Mater. Phys., 1995, 51, 6135-6138.

136 B. Zhao, S. F. Jin, S. Huang, N. Liu, J. Y. Ma, D. J. Xue, Q. Han, J. Ding, Q. Q. Ge, Y. Feng and J. S. Hu, J. Am. Chem. Soc., 2018, 140, 11716-11725.

137 K. Hong, Q. Van Le, S. Y. Kim and H. W. Jang, J. Mater. Chem. C, 2018, 6, 2189-2209.

138 Y. Wei, Z. Cheng and J. Lin, Chem. Soc. Rev., 2019, 48, 310-350.

139 L. Protesescu, S. Yakunin, M. I. Bodnarchuk, F. Krieg, R. Caputo, C. H. Hendon, R. X. Yang, A. Walsh and M. V. Kovalenko, Nano Lett., 2015, 15, 3692-3696.

140 F. Bertolotti, L. Protesescu, M. V. Kovalenko, S. Yakunin, A. Cervellino, S. J. L. Billinge, M. W. Terban, J. S. Pedersen, N. Masciocchi and A. Guagliardi, ACS Nano, 2017, 11, 3819-3831.

141 R. X. Yang and L. Z. Tan, J. Chem. Phys., 2020, 152, 034702. 142 P. Cottingham and R. L. Brutchey, Chem. Mater., 2018, 30, 6711-6716.

143 P. Cottingham and R. L. Brutchey, Chem. Commun., 2016, 52, 5246-5249.
144 L. Liu, R. Zhao, C. Xiao, F. Zhang, F. Pevere, K. Shi, H. Huang, H. Zhong and I. Sychugov, J. Phys. Chem. Lett., 2019, 10, 5451-5457.

145 M. C. Brennan, M. Kuno and S. Rouvimov, Inorg. Chem., 2019, 58, 1555-1560.

146 B. D. Hamilton, J.-M. Ha, M. A. Hillmyer and M. D. Ward, Acc. Chem. Res., 2012, 45, 414-423.

147 Q. Jiang and M. D. Ward, Chem. Soc. Rev., 2014, 43, 2066-2079.

148 B. D. Hamilton, J. M. Ha, M. A. Hillmyer and M. D. Ward, Acc. Chem. Res., 2012, 45, 414-423.

149 S. Lee, J. Feldman and S. S. Lee, Cryst. Growth Des., 2016, 16, 4744-4751.

150 X. Kong, K. Shayan, S. Lee, C. Ribeiro, S. Strauf and S. S. Lee, Nanoscale, 2018, 10, 8320-8328.

151 S. Ma, S. H. Kim, B. Jeong, H. C. Kwon, S. C. Yun, G. Jang, H. Yang, C. Park, D. Lee and J. Moon, Small, 2019, 15, 1-12.

152 X. Kong, K. Shayan, S. Hua, S. Strauf and S. S. Lee, ACS Appl. Energy Mater., 2019, 2, 2948-2955.

153 A. Waleed, M. M. Tavakoli, L. Gu, S. Hussain, D. Zhang, S. Poddar, Z. Wang, R. Zhang and Z. Fan, Nano Lett., 2017, 17, 4951-4957.

154 L. Gu, D. Zhang, M. Kam, Q. Zhang, S. Poddar, Y. Fu, X. Mo and Z. Fan, Nanoscale, 2018, 10, 15164-15172.

155 Q. Li, L. Zhang, Z. Chen and Z. Quan, J. Mater. Chem. A, 2019, 7, 16089-16108.

156 Y. Lee, D. B. Mitzi, P. W. Barnes and T. Vogt, Phys. Rev. B: Condens. Matter Mater. Phys., 2003, 68, 020103.

157 G. Liu, L. Kong, W. Yang and H. K. Mao, Mater. Today, 2019, 27, 91-106.

158 M. Szafrański and A. Katrusiak, J. Phys. Chem. Lett., 2017, 8, 2496-2506.

159 X. Lü, W. Yang, Q. Jia and H. Xu, Chem. Sci., 2017, 8, 6764-6776.

160 A. Jaffe, Y. Lin and H. I. Karunadasa, ACS Energy Lett., 2017, 2, 1549-1555.

161 L. Wang, K. Wang, G. Xiao, Q. Zeng and B. Zou, J. Phys. Chem. Lett., 2016, 7, 5273-5279.

162 L. Zhang, L. Wang, K. Wang and B. Zou, J. Phys. Chem. C, 2018, 122, 15220-15225.

163 L. Zhang, Q. Zeng and K. Wang, J. Phys. Chem. Lett., 2017, 8, 49.

164 G. Yuan, S. Qin, X. Wu, H. Ding and A. Lu, Phase Transitions, 2018, 91, 38-47.

165 M. Coduri, T. A. Strobel, M. Szafran, A. Katrusiak, A. Mahata, F. Cova, S. Bonomi, E. Mosconi, F. De Angelis and L. Malavasi, J. Phys. Chem. Lett., 2019, 10, 25.

166 Y. Wang, X. Lü, W. Yang, T. Wen, L. Yang, X. Ren, L. Wang, Z. Lin and Y. Zhao, DOI: 10.1021/jacs.5b06346.

167 J. Fang, S. Jiang, Y. Fang, R. Li, H. Xiao, J. Crowley, C. Wang, T. J. White, W. A. Goddard, Z. Wang, T. Baikie and J. Fang, Angew. Chem., Int. Ed., 2016, 55, 6540-6544.

168 X. Lü, Y. Wang, C. C. Stoumpos, Q. Hu, X. Guo, H. Chen, L. Yang, J. S. Smith, W. Yang, Y. Zhao, H. Xu, M. G. Kanatzidis and Q. Jia, Adv. Mater., 2016, 28, 8663-8668. 
169 L. Wang, K. Wang and B. Zou, J. Phys. Chem. Lett., 2016, 7, 2556-2562.

170 H. Zhu, T. Cai, M. Que, J. P. Song, B. M. Rubenstein, Z. Wang and O. Chen, J. Phys. Chem. Lett., 2018, 9, 4199-4205.

171 A. Jaffe, Y. Lin, C. M. Beavers, J. Voss, W. L. Mao and H. I. Karunadasa, ACS Cent. Sci., 2016, 2, 201-209.

172 M. Szafrański and A. Katrusiak, J. Phys. Chem. Lett., 2016, 7, 3458-3466.

173 L. Kong, G. Liua, J. Gong, Q. Hu, R. D. Schaller, P. Dera, D. Zhang, Z. Liu, W. Yang, K. Zhu, Y. Tang, C. Wang, S. H. Wei, T. Xu and H. K. Mao, Proc. Natl. Acad. Sci. U. S. A., 2016, 113, 8910-8915.

174 F. Capitani, C. Marini, S. Caramazza, P. Postorino, G. Garbarino, M. Hanfland, A. Pisanu, P. Quadrelli and L. Malavasi, J. Appl. Phys., 2016, 119, 185901.

175 A. Halder, Y. Rakita, D. Cahen and S. K. Sarkar, J. Phys. Chem. Lett., 2020, 11, 1473-1476.

176 G. Liu, L. Kong, J. Gong, W. Yang, H. Mao, Q. Hu, Z. Liu, R. D. Schaller, D. Zhang and T. Xu, Adv. Funct. Mater., 2017, 27, 1604208.

177 S. Bonomi, I. Tredici, B. Albini, P. Galinetto, A. Rizzo, A. Listorti, U. A. Tamburini and L. Malavasi, Chem. Commun., 2018, 54, 13212-13215.

178 G. Liu, J. Gong, L. Kong, R. D. Schaller, Q. Hu, Z. Liu, S. Yan, W. Yang, C. C. Stoumpos, M. G. Kanatzidis, H. K. Mao and T. Xu, Proc. Natl. Acad. Sci. U. S. A., 2018, 115, 8076-8081.

179 G. Liu, L. Kong, P. Guo, C. C. Stoumpos, Q. Hu, Z. Liu, Z. Cai, D. J. Gosztola, H. K. Mao, M. G. Kanatzidis and R. D. Schaller, ACS Energy Lett., 2017, 2, 2518-2524.

180 Y. H. Chang, K. Matsuishi and C. H. Park, J. Korean Phys. Soc., 2004, 44, 889-893.

181 F. Brivio, A. B. Walker and A. Walsh, APL Mater., 2013, 1, 042111.

182 C. Grote and R. F. Berger, J. Phys. Chem. C, 2015, 119, 22832-22837.

183 R. Prasanna, A. Gold-Parker, T. Leijtens, B. Conings, A. Babayigit, H. G. Boyen, M. F. Toney and M. D. McGehee, J. Am. Chem. Soc., 2017, 139, 11117-11124.

184 G. Mannino, I. Deretzis, E. Smecca, A. La Magna, A. Alberti, D. Ceratti and D. Cahen, J. Phys. Chem. Lett., 2020, 11, 2490-2496.

185 C. J. Bartel, C. Sutton, B. R. Goldsmith, R. Ouyang, C. B. Musgrave, L. M. Ghiringhelli and M. Scheffler, Sci. Adv., 2019, 5, eaav0693.

186 M. Becker, T. Klüner and M. Wark, Dalton Trans., 2017, 46, 3500-3509.

187 J. L. Knutson, J. D. Martin and D. B. Mitzi, Inorg. Chem., 2005, 44, 4699-4705.

188 M. R. Filip, G. E. Eperon, H. J. Snaith and F. Giustino, Nat. Commun., 2014, 5, 1-9.

189 N. Pellet, P. Gao, G. Gregori, T.-Y. Yang, M. K. Nazeeruddin, J. Maier and M. Grätzel, Angew. Chem., 2014, 126, 3215-3221.

190 J. H. Noh, S. H. Im, J. H. Heo, T. N. Mandal and S. Il Seok, Nano Lett., 2013, 13, 1764-1769.
191 A. Walsh, J. Phys. Chem. C, 2015, 119, 5755-5760.

192 D. Luo, L. Yu, H. Wang, T. Zou, L. Luo, Z. Liu and Z. Lu, $R S C$ Adv. , 2015, 5, 85480-85485.

193 A. K. Jena, A. Kulkarni and T. Miyasaka, Chem. Rev., 2019, 119, 3036-3103.

194 Z. Li, M. Yang, J.-S. Park, S.-H. Wei, J. J. Berry and K. Zhu, Chem. Mater., 2016, 28, 284-292.

195 G. E. Eperon, K. H. Stone, L. E. Mundt, T. H. Schloemer, S. N. Habisreutinger, S. P. Dunfield, L. T. Schelhas, J. J. Berry and D. T. Moore, ACS Energy Lett., 2020, 5, 1856-1864.

196 J. H. Noh, S. H. Im, J. H. Heo, T. N. Mandal and S. Il Seok, Nano Lett., 2013, 13, 1764-1769.

197 A. Francisco-López, B. Charles, O. J. Weber, M. I. Alonso, M. Garriga, M. Campoy-Quiles, M. T. Weller and A. R. Goñi, J. Phys. Chem. Lett., 2019, 10, 2971-2977.

198 V. D’Innocenzo, G. Grancini, M. J. P. Alcocer, A. R. S. Kandada, S. D. Stranks, M. M. Lee, G. Lanzani, H. J. Snaith and A. Petrozza, Nat. Commun., 2014, 5, 1-6.

199 Y. Yamada, T. Nakamura, M. Endo, A. Wakamiya and Y. Kanemitsu, Appl. Phys. Express, 2014, 7, 032302.

200 W. Zhang, M. Saliba, S. D. Stranks, Y. Sun, X. Shi, U. Wiesner and H. J. Snaith, Nano Lett., 2013, 13, 4505-4510.

201 R. L. Milot, G. E. Eperon, H. J. Snaith, M. B. Johnston and L. M. Herz, Adv. Funct. Mater., 2015, 25, 6218-6227.

202 H. Diab, G. Trippé-Allard, F. Lédée, K. Jemli, C. Vilar, G. Bouchez, V. L. R. Jacques, A. Tejeda, J. Even, J. S. Lauret, E. Deleporte and D. Garrot, J. Phys. Chem. Lett., 2016, 7, 5093-5100.

203 J. H. Lee, N. C. Bristowe, J. H. Lee, S. H. Lee, P. D. Bristowe, A. K. Cheetham and H. M. Jang, Chem. Mater., 2016, 28, 4259-4266.

204 Y. Jiang, A. M. Soufiani, A. Gentle, F. Huang, A. Ho-Baillie and M. A. Green, Appl. Phys. Lett., 2016, 108, 061905.

205 M. N. F. Hoque, N. Islam, Z. Li, G. Ren, K. Zhu and Z. Fan, ChemSusChem, 2016, 9, 2692-2698.

206 C. Quarti, E. Mosconi, J. M. Ball, V. D’Innocenzo, C. Tao, S. Pathak, H. J. Snaith, A. Petrozza and F. De Angelis, Energy Environ. Sci., 2016, 9, 155-163.

207 W. A. Saidi, S. Poncé and B. Monserrat, J. Phys. Chem. Lett., 2016, 7, 5247-5252.

208 J. Y. Yang and M. Hu, J. Phys. Chem. Lett., 2017, 8, 3720-3725.

209 S. X. Tao, X. Cao and P. A. Bobbert, Sci. Rep., 2017, 7, 1-9. 210 J. Kim, S. C. Lee, S. H. Lee and K. H. Hong, J. Phys. Chem. C, 2015, 119, 4627-4634.

211 D. Ghosh, A. Aziz, J. A. Dawson, A. B. Walker and M. S. Islam, Chem. Mater., 2019, 31, 4063-4071.

212 L. M. Herz, J. Phys. Chem. Lett., 2018, 9, 6853-6863.

213 J. Peng, Y. Chen, K. Zheng, T. Pullerits and Z. Liang, Chem. Soc. Rev., 2017, 46, 5714-5729.

214 M. C. Gélvez-Rueda, D. H. Cao, S. Patwardhan, N. Renaud, C. C. Stoumpos, G. C. Schatz, J. T. Hupp, O. K. Farha, T. J. Savenije, M. G. Kanatzidis and F. C. Grozema, J. Phys. Chem. C, 2016, 120, 16577-16585. 
215 H. Wang, L. Whittaker-Brooks and G. R. Fleming, J. Phys. Chem. C, 2015, 119, 19590-19595.

216 M. C. Gélvez-Rueda, N. Renaud and F. C. Grozema, J. Phys. Chem. C, 2017, 121, 23392-23397.

217 V. M. Caselli, M. Fischer, D. Meggiolaro, E. Mosconi, F. De Angelis, S. D. Stranks, A. Baumann, V. Dyakonov, E. M. Hutter and T. J. Savenije, J. Phys. Chem. Lett., 2019, 10, 5128-5134.
218 E. M. Mozur, J. C. Trowbridge, A. E. Maughan, M. J. Gorman, C. M. Brown, T. R. Prisk and J. R. Neilson, ACS Mater. Lett., 2019, 1, 260-264.

219 H. Zhang, X. Qiao, Y. Shen, T. Moehl, S. M. Zakeeruddin, M. Grätzel and M. Wang, J. Mater. Chem. A, 2015, 3, 11762-11767.

220 J. Peng, Y. Sun, Y. Chen, Y. Yao and Z. Liang, ACS Energy Lett., 2016, 1, 1000-1006. 